\title{
Using JABOWA-3 for forest growth and yield predictions under diverse forest conditions of Nova Scotia, Canada
}

\author{
by M. Irfan Ashraf ${ }^{1,2}$ Charles P.-A. Bourque ${ }^{1}$, David A. MacLean ${ }^{1}$, Thom Erdle ${ }^{1}$ and Fan-Rui Meng1,2
}

\begin{abstract}
Empirical growth and yield models developed from historical data are commonly used in developing long-term strategic forest management plans. Use of these models rests on an assumption that there will be no future change in the tree growing environment. However, major impacts on forest growing conditions are expected to occur with climate change. As a result, there is a pressing need for tools capable of incorporating outcomes of climate change in their predictions of forest growth and yield. Process-based models have this capability and may, therefore, help to satisfy this requirement. In this paper, we evaluate the suitability of an ecological, individual-tree-based model (JABOWA-3) in generating forest growth and yield projections for diverse forest conditions across Nova Scotia, Canada. Model prediction accuracy was analyzed statistically by comparing modelled with observed basal area and merchantable volume changes for 35 permanent sample plots (PSPs) measured over periods of at least 25 years. Generally, modelled basal area and merchantable volume agreed fairly well with observed data, yielding coefficients of determination $\left(r^{2}\right)$ of 0.97 and 0.94 and model efficiencies (ME) of 0.96 and 0.93 , respectively. A Chi-square test was performed to assess model accuracy with respect to changes in species composition. We found that $83 \%$ of species-growth trajectories based on measured basal area were adequately modelled with JABOWA-3 $(P>0.9)$. Model-prediction accuracy, however, was substantially reduced for those PSPs altered by some level of disturbance. In general, JABOWA-3 is much better at providing forest yield predictions, subject to the availability of suitable climatic and soil information.
\end{abstract}

Key words: forest model, growth and yield predictions, individual-tree-based model, model-accuracy assessment, statistical-performance indicators

\begin{abstract}
RÉSUMÉ
On se sert couramment de modèles empiriques de croissance élaborés à partir de données historiques pour faire des plans stratégiques d’aménagement forestier à long terme. L'utilisation de ces modèles repose sur l'hypothèse que le milieu de croissance ne changera pas dans le futur. Or, on sattend à ce que les changements climatiques modifient considérablement les conditions de croissance en forêt. Il y a donc un besoin urgent de mettre au point des outils capable de tenir compte les effets dus aux changements climatiques dans la prévision de la croissance et du rendement en forêt. Les modèles de procédés ont cette capacité et peuvent donc être d'une aide précieuse à cette fin. Dans cet article, nous évaluons la pertinence d'un modèle écologique par pied d’arbre (JABOWA-3) pour effectuer des prévisions de croissance et de rendement en forêt dans diverses conditions forestières de la Nouvelle-Écosse, au Canada. On a évalué de façon statistique la précision des prévisions obtenues avec ce modèle en comparant les changements de surface terrière et de volume marchand à partir de 35 placettes permanentes (PEP) mesurées sur des périodes d’au moins 25 ans. De façon générale, la surface terrière et le volume marchand obtenus avec le modèle correspondaient assez bien avec les résultats observés, donnant des coefficients de détermination (' 2 ) de 0,97 et 0,94 et une efficacité de modèle (ME) de 0,96 et 0,93 respectivement. Nous avons aussi effectué un test de chi carré afin d'évaluer la précision des modèles par rapport aux changements dans la composition forestière. Nous avons constaté que $83 \%$ des trajectoires de croissance par essence évaluées à partir des mesures de surface terrière dans les parcelles étaient représentées adéquatement par JABOWA-3 ( $\mathrm{P}>0,9)$. La précision des prévisions avec le modèle diminue de façon appréciable pour les PEP ayant subi un certain niveau de perturbation. En général, JABOWA-3 réussit beaucoup mieux à faire des prévisions de rendement des forêts, dans la mesure où l'on dispose de renseignements convenables sur les sols et sur le climat.
\end{abstract}

Mots clés: Modèle forestier, prévisions de croissance et de rendement, modèles par arbre, évaluation de la précision d'un modèle, indicateur statistique de performance

\footnotetext{
${ }^{1}$ Faculty of Forestry and Environmental Management, P.O. Box 4400, University of New Brunswick, Fredericton, NB E3B 5A3 Canada.

${ }^{2}$ Faculty of Forestry, University of Arid-Agriculture, Rawalpindi, Pakistan.

${ }^{3}$ Corresponding author. E-mail: fmeng@unb.ca
} 


\section{Introduction}

Growth and yield models have been extensively used in predicting forest dynamics. Their role in forest management is like a "pathfinder" in searching for the best management scenario and to provide information for long-term planning and policy-making (Landsberg 2003a). Current growth and yield models have high spatial and temporal resolution, and are now a fundamental part of decision support systems in forestry (Burkhart 1990, Mohren and Burkhart 1994). Many growth and yield models currently in use by various government departments and forest companies are empirical in nature (Yaussy 2000, Landsberg 2003a), with estimates of yield generally provided as a function of current tree dimensions, stand density, and site quality (Liu and Ashton 1995, Peng 2000).

Since empirical growth and yield models (regression models) are developed from vast quantities of local historical data (Landsberg 2003a, Sun et al. 2007) they provide accurate, but site-specific predictions (Monserud 2003). The principal assumption behind these empirical models is a constant growing environment (Vanclay 1994, Yaussy 2000, Monserud 2003, Kimmins 2004). Site index, an integrated descriptor of forest growing conditions, remains static in most growth and yield models (Meldahl et al. 1988, Johnsen et al. 2001). As the focus of empirical models is to provide information for management, their outputs are usually given as timber yield (i.e., merchantable volume) and stand structure (diameter class) as a function of time (Porté and Bartelink 2002, Burkhart 2003, Mendoza and Vanclay 2008). Their simple data requirements, relatively high prediction accuracy across regions, and compatibility with management needs, have made these models popular in forestry (Makela 1992, Vanclay 1994, Kimmins et al. 1995, Battaglia and Sands 1998, Johnsen et al. 2001).

Despite all these positive features, because of the inherent assumption of constant growing conditions, empirical models have limited predictive capability when changes occur in the tree growing environment, management conditions, or disturbance regimes (Kimmins 1990, 2004, Monserud 2003, Pinjuv et al. 2006). This limitation is caused by the fact that empirical models rely on historical data in their elaboration (Johnsen et al. 2001, Landsberg 2003a). As a result, predictions by empirical models are potentially biased when faced with a rapidly changing environment or management regime (Mohren and Burkhart 1994, Burkhart 2003).

Climate change is currently occurring and expected to continue into the future at unprecedented rates. Forest ecosystems are expected to be affected by rises in atmospheric temperature, changes in precipitation as to the amounts fallen and deposition patterns (IPCC 2007). Current empirical models do not have the capability to accommodate outcomes of climate change in their production of growth and yield predictions for changing environments (Schwalm and Ek 2002). Nor can they be used to predict growth and yield in the absence of historical data, as for instance, when (i) new lands are developed for plantations, or (ii) a forest company wants to evaluate the productivity of a parcel of land before procuring it (Landsberg 2003a, Miehle et al. 2009).

In contrast, process-based models can simulate system processes when growing conditions vary over time (Miehle et al. 2009). These models are constructed based on cause and effect relationships that control tree growth (Kimmins and Sollins 1989, Korzukhin et al. 1996). In process-based mod- els, parameter values are commonly associated with key physiological processes driven by primary environmental variables (Battaglia and Sands 1998, Peng 2000, Johnsen et al. 2001).

Gap (individual-tree-based) models form the most successful and largest family of process-based models, with over 60 variants of JABOWA ${ }^{\circ}$, first released in 1972 (Botkin 1993, Botkin and Schenk 1996, Mladenoff 2004). Gap models employ ecological principles and account for tree physiological processes to predict forest succession over time (Liu and Ashton 1995). These individual-tree models were initially developed to study tree growth and ecological succession (Botkin et al. 1972a, Shugart and West 1980, Botkin 1993). In gap models, forest dynamics are modelled as a group of patches (or gaps) that take into account inter-tree competition and key environmental factors, such as available sunlight, air temperature, and soil moisture (Peng 2000, Pretzsch 2009). JABOWA-type models have been widely used to assess the response of projected climate change on forests and have clear advantages over their empirical counterparts (Hinckley et al. 1996, Shugart 2002, Ngugi and Botkin 2011). Since the presentation of physiological processes in most gap models is made simple (Larocque 2009), insertion of detailed climateresponse functions would potentially yield more accurate predictions of forest response under conditions of climate change (Loehle and LeBlanc 1996, Norby et al. 2001).

Process-based models are rarely used in forest management because of their excessive complexity and intensive data requirement (Landsberg 2003a,b, Kimmins 2004). Historically, process-based models have been used more often in research and education (Mohren and Burkhart 1994). In this study, we evaluate the suitability of an individual-tree-based model, namely JABOWA-3, in producing forest growth and yield predictions for Nova Scotia, Canada.

\section{Methods \\ Model description}

The initial JABOWA model was originally developed for northern hardwood forests of the Hubbard Brook Ecosystem in New Hampshire, USA. The model has since been applied globally and has undergone many important enhancements (Botkin et al. 1972a,b, Botkin 1993). JABOWA-3 uses a small plot (i.e., $0.01-0.08$ ha) to model forest growth and succession (Kimmins 2004). Individual-tree growth is determined as a function of potential diameter growth, which is, in turn, determined by current and maximum reported diameter relative to species (Monserud 2003). Diameter growth is controlled by four modifiers of species interaction based on species response to sunlight, growing degree-day sums, soil moisture, and soil nutrient availability (Botkin 1993). The main assumptions of JABOWA-3 are (Liu and Ashton 1995): (i) tree diameter increases at a maximum rate under optimal conditions and is influenced by maximum tree age, diameter, and height, and potential growing-limits tree species are recorded to achieve under favourable conditions; and (ii) tree growth is controlled by both abiotic and biotic environmental factors.

Conceptual flow of information in JABOWA-3, including important inputs and outputs, are shown in Fig. 1. Tree growth is defined by a "fundamental growth equation" described in Botkin (1993) and Porté and Bartelink (2002), i.e., 


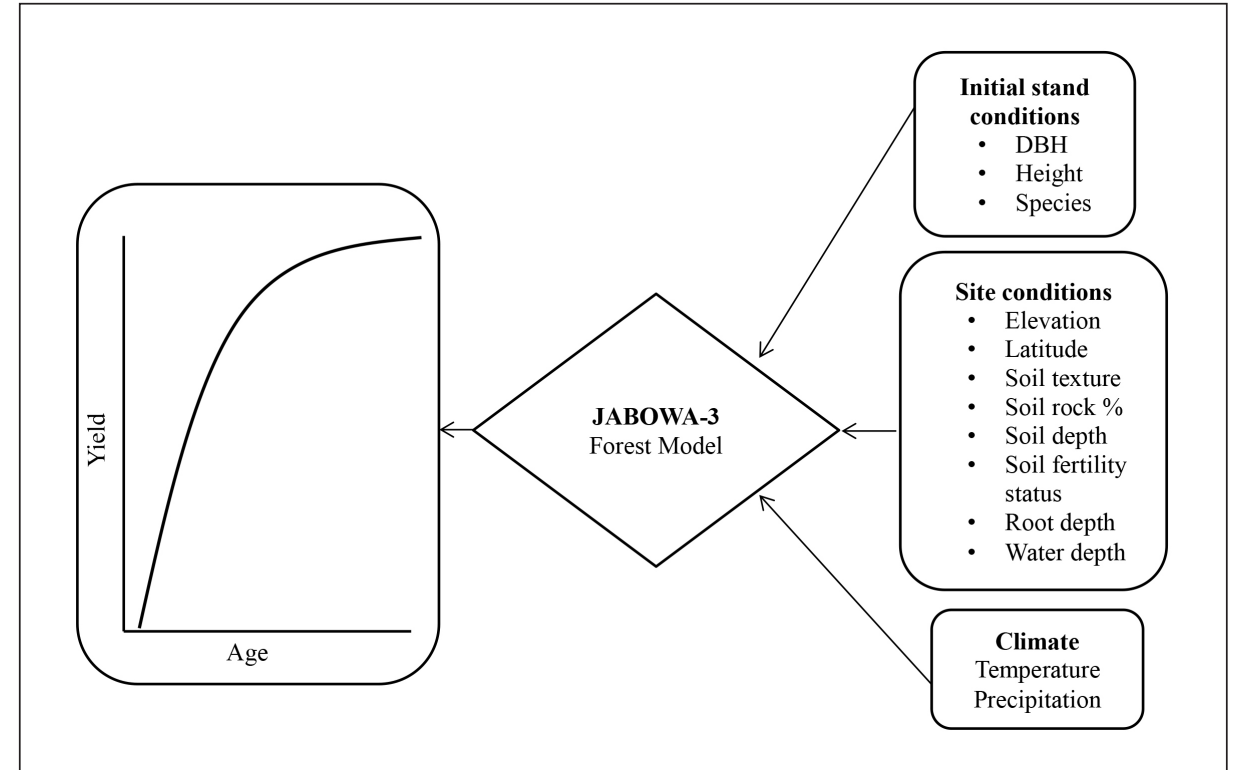

Fig.1. Data flow in JABOWA-3.

$$
\text { [1] } \Delta\left(\mathrm{D}^{2} * \mathrm{H}\right)=\mathrm{R} * \mathrm{LA}\left(1-\frac{\mathrm{DH}}{\mathrm{D}_{\max } \mathrm{i} * \mathrm{H}_{\max } \mathrm{i}}\right) * \mathrm{f}(\mathrm{e})
$$

where $D$ and $H$ are the tree diameter (at breast height) and height, $D_{\max i}$ and $H_{\max i}$ are the maximum known diameter and height for trees of species $i$, LA is tree leaf area, $\mathrm{f}(\mathrm{e})$ is an environmental-response function, and $\mathrm{R}$ is an equation constant. A more comprehensive description of the model is given in Botkin (1993) and Botkin and Schenk (1996).

\section{Study area and data requirements}

Forests of Nova Scotia, located between $43^{\circ} 27^{\prime} \mathrm{N}$ to $46^{\circ} 01^{\prime} \mathrm{N}$ (latitude) and $59^{\circ} 38^{\prime} \mathrm{W}$ to $66^{\circ} 16^{\prime} \mathrm{W}$ (longitude) were the subject of study (Fig. 2). Forests cover $77 \%$ of the province and are dominated by young, even-aged stands (0-40 years) due to intensive harvests in the past (NSDNR 2008, Woodbridge Associates 2011). Out of the total 4.27 million ha of forest area, $50 \%$ is classified as softwood, $11 \%$ hardwood, $25 \%$ mixedwood, and the remaining $14 \%$ as unclassified forests (NSDNR 2008). Major tree species by volume are spruce (Picea species; 35\%), balsam fir (Abies balsamea (L.); $22 \%$ ), and broadleaved species (30\%; NSDNR 2004). Nova Scotia is in the Atlantic Maritime Ecozone, which consists of hilly areas with poor soils and coastal plains with richer soils. Average annual precipitation is $1425 \mathrm{~mm}$ along the coast and $1000 \mathrm{~mm}$ in the interior of the province. Mean temperature ranges from $-10^{\circ} \mathrm{C}$ to $-2.5^{\circ} \mathrm{C}$ in the cold months of the year and up to $18^{\circ} \mathrm{C}$ in warmer months.

Studies related to development, calibration and validation of forest-simulation models require two main types of information: forest inventory and environmental data (Liu and
Ashton 1995). Historical tree measurements were obtained from the Nova Scotia Department of Natural resources (NSDNR) as permanent sample plot (PSP) data, and past temperature and precipitation data (Environment Canada 2011). Soil-related data, such as soil depth, texture, and \% rock outcrop were obtained from the Canadian Soil Information Service (Agriculture and AgriFood Canada 2011).

\section{Model calibration}

Prior to model evaluation, an initial calibration was performed with an independent dataset not applied in model validation. A standard calibration procedure was adopted; repeating runs, while manually adjusting parameters to find the best possible fit (within an accepted level of accuracy) to observed species basal area (BA). Parameters for growth rate under optimal conditions (G), coefficient of leaf weight to tree diameter (C), and upper and lower limits of growing degree-day sums (DDMAX, DDMIN) were modified for most species considered. DDMAX and DDMIN represent growing degree-day sums

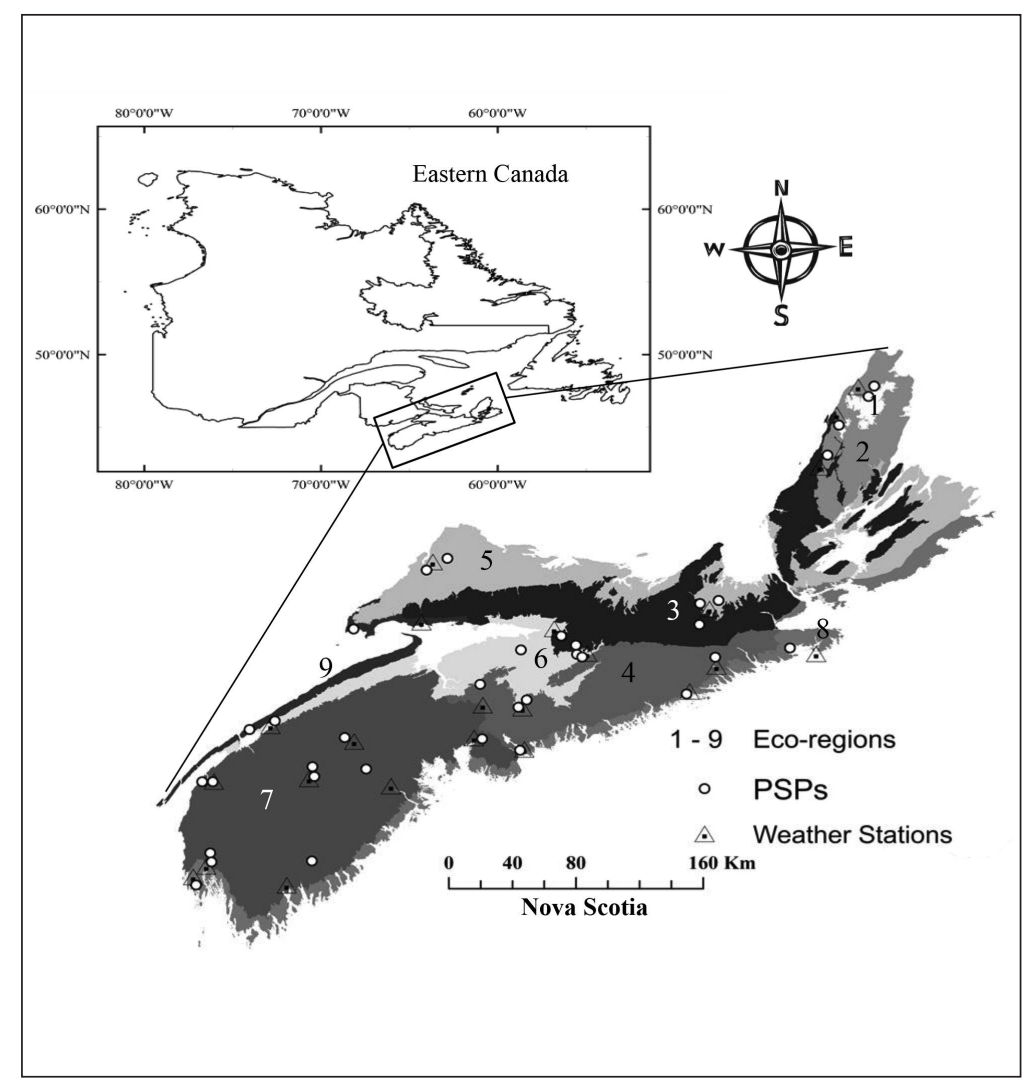

Fig. 2. Study area showing ecoregions (for names, see Table 1) and 35 PSPs and weather stations relevant to the study. 
along a species' geographical range's southern and northern limits. Adjustments were made in DDMAX and DDMIN whenever the model was applied to a new geographic region of the province. Additional detail concerning the calibration of JABOWA-3 is given in Botkin (1993).

\section{PSP selection}

NSDNR maintains over 3000 inventory-designated PSPs of 0.04 ha, circular in shape with a radius of $11.35 \mathrm{~m}$ and randomly placed throughout the province. Data collected from PSPs include traditional inventory attributes (e.g., tree height, diameter at breast height), as well as data associated with biodiversity, ecosystem management, and forest protection (NSDNR 2006). In general, PSP characteristics are assessed every five years; some gaps may appear in the data for various reasons. Under the hierarchical Ecological Land Classification (ELC) system, Nova Scotia is divided into nine ecoregions (Marshall and Schut 1999, Neily et al. 2003). All PSPs were grouped according to the nine ecoregions, and 35 PSPs were randomly selected based on species composition and availability of recorded information for a minimal uninterrupted period of at least 25 years with no history of harvesting. There were no restrictions around stand age in the selection process, since age was not recorded uniformly across all PSPs. Also, age is fairly difficult to define for uneven-aged stands. Number of PSPs selected from each ecoregion was proportional to the ecoregions' surface area. A list of PSPs selected and their overall species composition is presented in Table 1.

Table 1. Description of 35 permanent sample plots grouped into nine ecoregions showing species composition (\% basal area]

\begin{tabular}{|c|c|c|c|c|c|c|c|c|c|c|c|c|c|c|c|c|c|c|}
\hline \multirow[b]{2}{*}{ Ecoregion \# } & \multirow[b]{2}{*}{ Ecoregion Name } & \multirow[b]{2}{*}{ PSP \# } & \multicolumn{16}{|c|}{ Species and average observed BA (\%) } \\
\hline & & & BE & $\mathrm{BF}$ & BS & EH & EL & GB & LA & RO & $\mathbf{R M}$ & RS & SM & TA & WB & WP & WS & YB \\
\hline \multirow[t]{2}{*}{1} & Cape Breton & 615 & - & - & - & - & 20 & - & - & - & - & 80 & - & - & - & - & - & - \\
\hline & Taiga & 1467 & - & 100 & - & - & - & - & - & - & - & - & - & - & - & - & - & - \\
\hline \multirow[t]{2}{*}{2} & Cape Breton & 846 & - & 30 & - & - & - & - & - & - & - & - & 23 & - & - & - & - & 47 \\
\hline & Highlands & 1535 & - & - & - & - & - & - & - & - & 33 & - & 67 & - & - & - & - & - \\
\hline \multirow[t]{4}{*}{3} & Nova Scotia & 96 & - & 36 & - & - & - & - & - & - & - & 2 & - & - & - & - & 62 & - \\
\hline & Uplands & 702 & - & 15 & - & - & - & - & - & - & - & - & - & - & - & - & 85 & - \\
\hline & & 847 & - & 79 & - & - & - & - & - & - & 5 & 16 & - & - & - & - & - & - \\
\hline & & 1626 & 46 & - & - & - & - & - & - & - & - & 54 & - & - & - & - & - & - \\
\hline \multirow[t]{6}{*}{4} & Eastern & 63 & - & - & - & 92 & - & - & - & 2 & - & 2 & - & - & 1 & 3 & - & - \\
\hline & & 460 & - & 6 & - & - & - & - & - & - & 7 & 85 & - & - & 2 & - & - & - \\
\hline & & 726 & - & 93 & - & - & - & - & - & - & - & 7 & - & - & - & - & - & - \\
\hline & & 760 & - & - & - & - & - & - & - & - & 10 & - & - & - & 32 & - & 58 & - \\
\hline & & 1041 & - & 39 & - & - & - & - & - & - & 10 & - & - & - & - & - & 17 & 34 \\
\hline & & 1361 & - & - & - & 93 & - & - & - & - & - & 5 & - & - & 2 & - & - & - \\
\hline \multirow[t]{3}{*}{5} & Northumberland & 429 & - & - & - & - & - & - & - & - & - & - & - & - & - & - & 100 & - \\
\hline & & 898 & - & - & - & - & - & - & 10 & - & 16 & 28 & - & 41 & 2 & - & 3 & - \\
\hline & & 958 & - & 58 & - & - & - & 2 & - & - & 25 & 6 & - & - & 5 & - & 2 & 2 \\
\hline \multirow[t]{4}{*}{6} & Central Lowlands & 570 & - & - & - & - & 1 & - & - & - & - & 99 & - & - & - & - & - & - \\
\hline & & 881 & - & 33 & - & - & - & - & - & - & 6 & 49 & - & - & - & - & 12 & - \\
\hline & & 1272 & - & 36 & - & - & - & - & - & - & 25 & 39 & - & - & - & - & - & - \\
\hline & & 1724 & - & - & - & - & - & - & - & - & - & - & - & - & - & - & 100 & - \\
\hline \multirow[t]{10}{*}{7} & Western & 74 & - & - & 49 & - & 51 & - & - & - & - & - & - & - & - & - & - & - \\
\hline & & 578 & - & 15 & - & - & - & - & - & 2 & 12 & 71 & - & - & - & - & - & - \\
\hline & & 735 & - & 66 & - & - & - & - & - & - & - & 34 & - & - & - & - & - & - \\
\hline & & 836 & - & 9 & - & - & 21 & 9 & - & - & 5 & 56 & - & - & - & - & - & - \\
\hline & & 893 & - & 25 & - & - & - & - & - & - & 75 & - & - & - & - & - & - & - \\
\hline & & 1098 & - & - & - & - & - & - & - & - & - & 100 & - & - & - & - & - & - \\
\hline & & 1130 & - & - & - & - & - & - & - & 95 & 5 & - & - & - & - & - & - & - \\
\hline & & 1291 & - & 12 & - & - & - & - & - & - & 35 & 40 & - & - & - & 13 & - & - \\
\hline & & 1559 & - & 8 & - & - & - & - & - & - & - & 82 & - & - & - & 10 & - & - \\
\hline & & 1718 & - & 21 & - & - & - & - & - & - & 35 & 44 & - & - & - & - & - & - \\
\hline \multirow[t]{2}{*}{8} & Atlantic Coastal & 123 & - & - & 100 & - & - & - & - & - & - & - & - & - & - & - & - & - \\
\hline & & 1022 & - & 3 & - & - & 12 & - & - & - & - & - & - & - & - & - & 85 & - \\
\hline \multirow[t]{2}{*}{9} & Fundy Shore & 368 & - & - & - & - & - & - & - & - & - & - & 100 & - & - & - & - & - \\
\hline & & 587 & - & - & - & - & - & - & - & - & 43 & 50 & 7 & - & - & - & - & - \\
\hline
\end{tabular}

${ }^{\text {aF }}$ or species scientific names and code abbreviations, consult Table 2. 


\section{Model evaluation}

Validation and verification are commonly used terms in model evaluation studies, but are often used differently as there is no agreement in the scientific community as to a "standard definition" of the terms (Botkin 1993, Oreskes et al.1994, Soares et al.1995, Vanclay and Skovsgaard 1997, Pretzsch 2009). In the context of this paper, we use the term "validation" to refer to the testing of accuracy by comparing model-generated values against recorded data in order to quantitatively assess model bias, precision, and accuracy (Pretzsch 2009). An initial logical verification of the model was completed following the principles outlined in Vanclay (1994) and Vanclay and Skovsgaard (1997).

An initial step for model validation was to define the criteria of evaluation (Robinson and Monserud 2003). As the focus of this study is to test the suitability of JABOWA-3 in producing reliable growth and yield predictions, we elected to use basal area (BA) and merchantable volume (MV) in our evaluation of the model. Basal area is a primary variable in forest quantitative assessment and ecological studies, and is often used as a measure of stand density (Botkin 1993, Robinson and Ek 2003). It is also used in silvicultural applications to quantify thinning and harvesting levels (Davis et al. 2001). Merchantable volume is also used in forestry and is commonly determined from BA and local volume tables. Our calculation of MV was based on Honer's volume tables, also used by NSDNR. The complete procedure, parameters, and specifications (i.e., minimum $\mathrm{DBH}$, stump height, top diameter) are available in Honer et al. (1983) for most tree species of Nova Scotia.

Two approaches, i.e., statistical analysis and model-efficiency testing, were used to examine the prediction performance of the model, in terms of (i) yield (five-year BA; $\mathrm{m}^{2} \mathrm{ha}^{-1}$, and $\mathrm{MV} ; \mathrm{m}^{3} \mathrm{ha}^{-1}$ ); (ii) growth (changes in five-year BA and $\mathrm{MV}$ ); and (3) species compositional changes (five-year BA as a function of species change over time). Growth was calculated with eq. 2 and eq. 3 , i.e.,

$$
\begin{aligned}
& \text { [2] } \text { Growth }_{B A}=B A_{(t+5)}-B A_{t} \\
& \text { [3] } \text { Growth }_{M V}=M V_{(t+5)}-M V_{t}
\end{aligned}
$$

where $B A_{t}$ and $M V_{t}$ are the basal area and merchantable volume at time " $t$ " and $B A_{(t+5)}$ and $M V_{(t+5)}$ are the BA and merchantable volume five years later.

Simulations for the 35 PSPs were generated using the initial inventory data and historical weather records by initializing the model once and then running the model for the entire period for which observations were available. Output of the model was based on the average of 50 sub-runs (iterations) per model run (one run per PSP) to lessen the effect of model stochasticity brought on by the model functions of mortality and ingrowth. Modelled BA and MV for each PSP were compared against their field-based counterparts for each five-year increment; all periods were considered of equal weight.

\section{Overall comparison of model accuracy}

The most commonly used statistical technique in assessing model performance has been centred on the application of linear regression on modelled and field values (Yang et al. 2004). Coefficient of determination $\left(r^{2}\right)$, intercept, and slope of fitted regression lines are useful indicators of the quality of prediction (Vanclay and Skovsgaard 1997). Overall model prediction accuracy was determined by fitting a linear regression model $\left(\mathrm{Y}=\mathrm{b}_{0}+\mathrm{b}_{1} \mathrm{X}\right)$ between modelled and observed BA $\left(\mathrm{m}^{2} \mathrm{ha}^{-1}\right), \mathrm{MV}\left(\mathrm{m}^{3} \mathrm{ha}^{-1}\right)$, BA growth, and MV growth. Estimated regression coefficients were analyzed by applying separate $t$ and $F$ tests (eq. 4 and eq. 5, respectively) to the individual quantities. Both tests were used to determine the statistical significance of slope for unity and intercept for zero (Montgomery et al. 2001, Yang et al. 2004).

$$
\begin{aligned}
& \text { [4] } \quad \mathrm{t}_{\text {stat (slope) }}=\frac{\left(\mathrm{b}_{1}-1\right)}{\sqrt{\left[\sum(\mathrm{Y}-\tilde{\mathrm{Y}})^{2} /(\mathrm{n}-2)\right] / \sum(\mathrm{X}-\overline{\mathrm{X}})^{2}}} \\
& \text { [5] } \quad \mathrm{F}_{\text {stat }}=\frac{\mathrm{n}\left(\mathrm{b}_{0}-0\right)^{2}+2 \sum \mathrm{X}\left(\mathrm{b}_{0}-0\right)\left(\mathrm{b}_{1}-1\right)+\sum \mathrm{X}^{2}\left(\mathrm{~b}_{1}-1\right)^{2}}{2 \sum(\mathrm{Y}-\tilde{\mathrm{Y}})^{2} /(\mathrm{n}-2)}
\end{aligned}
$$

where $b_{0}$ and $b_{1}$ are the intercept and slope of regression, $\overline{\mathrm{Y}}$ is the predicted value from $\mathrm{Y}=\mathrm{b}_{0}+\mathrm{b}_{1} \mathrm{X}, \mathrm{X}$ is the mean of the values of the independent variable $(\mathrm{X})$, and $n$ is number of comparison data points. In addition to $t_{\text {stats(intercept) }}$ BIAS (eq. 6), model efficiency (ME; eq. 7), and root mean square error (RMSE; eq. 8) were also estimated to get insight into the overall prediction accuracy of JABOWA-3. Model Efficiency was originally proposed by Nash and Sutcliffe (1970) and is an index with a range from $-\infty$ to 1 ; when $\mathrm{ME}=0$, the model is no better than a simple average of all the data and when ME $=1$, the model fits the observations perfectly (Soares et al. 1995, Vanclay and Skovsgaard 1997, Krause et al. 2005).

$$
\begin{aligned}
& \text { [6] } \text { BIAS }=\frac{\sum_{i=1}^{n}\left(O_{i j}-S_{i j}\right)}{n} \\
& \text { [7] } M E=1-\frac{\sum_{i=1}^{n}\left(O_{i j}-S_{i j}\right)^{2}}{\sum_{i=1}^{n}\left(O_{i j}-\bar{O}_{i}\right)^{2}} \\
& \text { [8] } \quad \text { RMSE }=\sqrt{\frac{\sum_{i=1}^{n}\left(O_{i j}-S_{i j}\right)^{2}}{n}}
\end{aligned}
$$

where $\mathrm{O}_{\mathrm{ij}}$ and $S_{i j}$ denote the observed and modelled BA of species $j$ at time interval $i$ in a particular PSP; and $O_{i}$ is the mean of the observed values for all PSPs, for all time periods.

\section{Individual stand comparisons for model accuracy}

Quality of model-predicted species composition (modelled vs. observed) was tested with a Chi-square $\left(\chi^{2}\right)$ test by comparing BA of each species over time. The $\chi^{2}$ test is commonly used to investigate the fit of categorical distributions, by determining how close an observed distribution matches the modelled distribution. In this test, species were considered categories and probability of distribution at different times was calculated on the basis of modelled and observed BA by species per PSP (eq. 9). Probability values range from 0 to 1 , where a value of 0 implies that there is significant difference between distributions being compared and 1, to perfectly matching distributions:

[9] $\chi^{2}=\sum_{\mathrm{i}=1}^{\mathrm{n}} \cdot \sum_{\mathrm{j}=1}^{\mathrm{m}} \frac{\left(\mathrm{o}_{\mathrm{ij}}-\mathrm{S}_{\mathrm{ij}}\right)^{2}}{\mathrm{~s}_{\mathrm{ij}}}$

where $m$ is the number of species, and $n$ is the number of 
time intervals. PSP-level accuracy for BA, MV, and BA growth and MV growth predictions were assessed using RMSE, BIAS, and ME by comparing modelled and observed data at five-year intervals. For growth analysis, disturbed species (dead down or dead standing, with no measurement) were removed from the data or the comparison was limited to the time period when data were available.

Results for ME, RMSE, and BIAS in BA, MV, and BA growth and MV growth analysis were summarised in four classes according to the range of values generated for each evaluation indicator. The 35 PSPs were then categorized according to these classes. In the BA yield and BA growth

Table 2. Tree species with scientific names and abbreviated species codes

\begin{tabular}{lll}
\hline Common names & Scientific names & Codes \\
\hline Balsam fir & Abies balsamea (L.) & BF \\
Beech & Fagus grandifolia Ehrh. & BE \\
Black spruce & Picea mariana (Mill.) BSP & BS \\
Eastern hemlock & Tsuga canadensis (L.) & EH \\
Eastern larch & Larix laricina (Du Roi) & EL \\
$\quad$ Tamarack) & K. Koch & \\
Grey birch & Betula populifolia Marsh. & GB \\
Large tooth aspen & Populus grandidentata Michx. & LA \\
Red oak & Quercus rubra L. & RO \\
Red maple & Acer rubrum L. & RM \\
Red spruce & Picea rubens Sarg. & RS \\
Sugar maple & Acer saccharum Marsh. & SM \\
Trembling aspen & Populus tremuloides_Michx. & TA \\
White birch & Betula papyrifera Marsh. & WB \\
White pine & Pinus strobes L. & WP \\
White spruce & Picea glauca (Moench) Voss & WS \\
Yellow birch & Betula alleghaniensis Britt. & YB \\
\hline
\end{tabular}

analysis, ME classes were defined "best" when values were between 0.75 and 1.00, "good" between 0.45 and 0.75 , "medium" between 0.0, 0.44, and "poor" when $<0.00$. Different limits were set for RMSE and BIAS classes based on the magnitude of yield and growth. In BA yield analysis, for RMSE "best" was defined as $\leq 1.00$, "good" between 1.01 and 2.00, "medium" between 2.01 and 4.00, and "poor" $>4.0$; for absolute BIAS, "best" was defined to occur when values were $\leq 0.50$, "good" between 0.51 and 1.50, "medium" between 1.51 and 3.00, and "poor" >3.00. In BA growth analysis, for RMSE "best" was defined as $\leq 0.50$, "good" between 0.51 and 1.00, "medium" between 1.01 and 2.00, and "poor" >2.0; for absolute BIAS "best" was defined as $\leq 0.25$, "good" between 0.26 and 0.55 , "medium" between 0.56 and 1.00, and "poor" $>$ 1.00. Evaluation-class limits for MV and MV growth are defined in Fig. 6. The "best", "medium" and "good" classes were considered as providing acceptable results.

The few PSPs that were involved in producing low prediction accuracy were further examined (by accessing NSDNRPSP description records) to determine reasons for discrepancy.

\section{Results}

Overall comparisons of the model accuracy for growth and yield Modelled vs. observed BA growth and yield data are presented in Fig. 3. Coefficients of determination $\left(r^{2}\right)$ for BA growth and BA yield were 0.70 and 0.97 , respectively. Most data points in the residual plot for BA yield were within the range of -2.5 to 2.5 , while for growth the range was -1.0 to 1.0. Similarly, Fig. 4 provides the results for the MV and MV growth analyses. The $r^{2}$ 's for MV growth and MV yield were 0.65 and 0.94 , respectively. Most data points in the MV residual plot were within the range of -20.0 to 20.0, while for MV growth the range was -5.0 to 5.0. Residual plot data (Fig. 3 and Fig. 4) were randomly dispersed along the horizontal axis,

Table 3. Overall evaluation of JABOWA-3 for basal area and merchantable-volume growth and yield based on 35 permanent sample plots from nine ecoregions of Nova Scotia

\begin{tabular}{|c|c|c|c|c|c|c|c|c|c|}
\hline & \multirow{3}{*}{$\begin{array}{c}\text { Data } \\
\text { points }^{\mathrm{a}} \\
(n)\end{array}$} & \multirow[b]{3}{*}{ BIAS } & \multirow[b]{3}{*}{ ME } & \multirow[b]{3}{*}{ RMSE } & \multirow{3}{*}{$\begin{array}{c}\text { Regression } \\
\text { coefficients } \\
\left(\mathrm{Y}=\mathrm{b}_{0}+\mathrm{b}_{1} \mathrm{X}\right)\end{array}$} & \multicolumn{4}{|c|}{$\begin{aligned} \text { Analysis for slope }\left(b_{1}\right) & =1 \text { and intercept }\left(b_{0}\right)=0 \\
a & =0.05\end{aligned}$} \\
\hline & & & & & & $\begin{array}{l}\text { Separ } \\
\quad(\mathbf{d f}\end{array}$ & $\begin{array}{l}\text { t-test } \\
-2)\end{array}$ & $\begin{array}{r}\text { Simı } \\
\text { F-test }(\mathrm{d})\end{array}$ & $\begin{array}{l}2 \text { and } n-2 \\
2 \text { aneous }\end{array}$ \\
\hline & & & & & & $t$ & $P$ & $F$ & $P$ \\
\hline $\begin{array}{l}\text { BA yield } \\
\left(\mathrm{m}^{2} \mathrm{ha}^{-1}\right)\end{array}$ & 721 & -0.17 & 0.96 & 1.73 & $\begin{array}{l}1.01 \\
0.12\end{array}$ & $\begin{array}{l}0.91 \\
1.50\end{array}$ & $\begin{array}{l}0.36 \\
0.13\end{array}$ & 1.70 & 0.18 \\
\hline 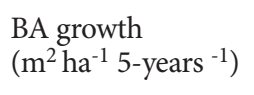 & 603 & 0.05 & 0.69 & 0.66 & $\begin{array}{l}0.69 \\
0.21\end{array}$ & $\begin{array}{l}-16.68 \\
7.75\end{array}$ & $\begin{array}{l}<0.05 \\
<0.05\end{array}$ & 52.65 & $<0.05$ \\
\hline $\begin{array}{l}\text { MV yield } \\
\left(\mathrm{m}^{3} \mathrm{ha}^{-1}\right)\end{array}$ & 721 & -3.06 & 0.93 & 13.99 & $\begin{array}{l}1.00 \\
2.89\end{array}$ & $\begin{array}{l}0.48 \\
4.74\end{array}$ & $\begin{array}{c}0.63 \\
<0.05\end{array}$ & 13.55 & $<0.05$ \\
\hline $\begin{array}{l}\text { MV growth } \\
\left(\mathrm{m}^{3} \text { ha }^{-1} 5 \text {-years }\right. \\
\end{array}$ & 603 & -0.33 & 0.64 & 4.51 & $\begin{array}{l}0.68 \\
1.97\end{array}$ & $\begin{array}{c}-15.71 \\
10.56\end{array}$ & $\begin{array}{l}<0.05 \\
<0.05\end{array}$ & 53.67 & $<0.05$ \\
\hline
\end{tabular}

${ }^{\mathrm{a} C}$ Comparison data points

ME: model efficiency

RMSE: root mean squared error 

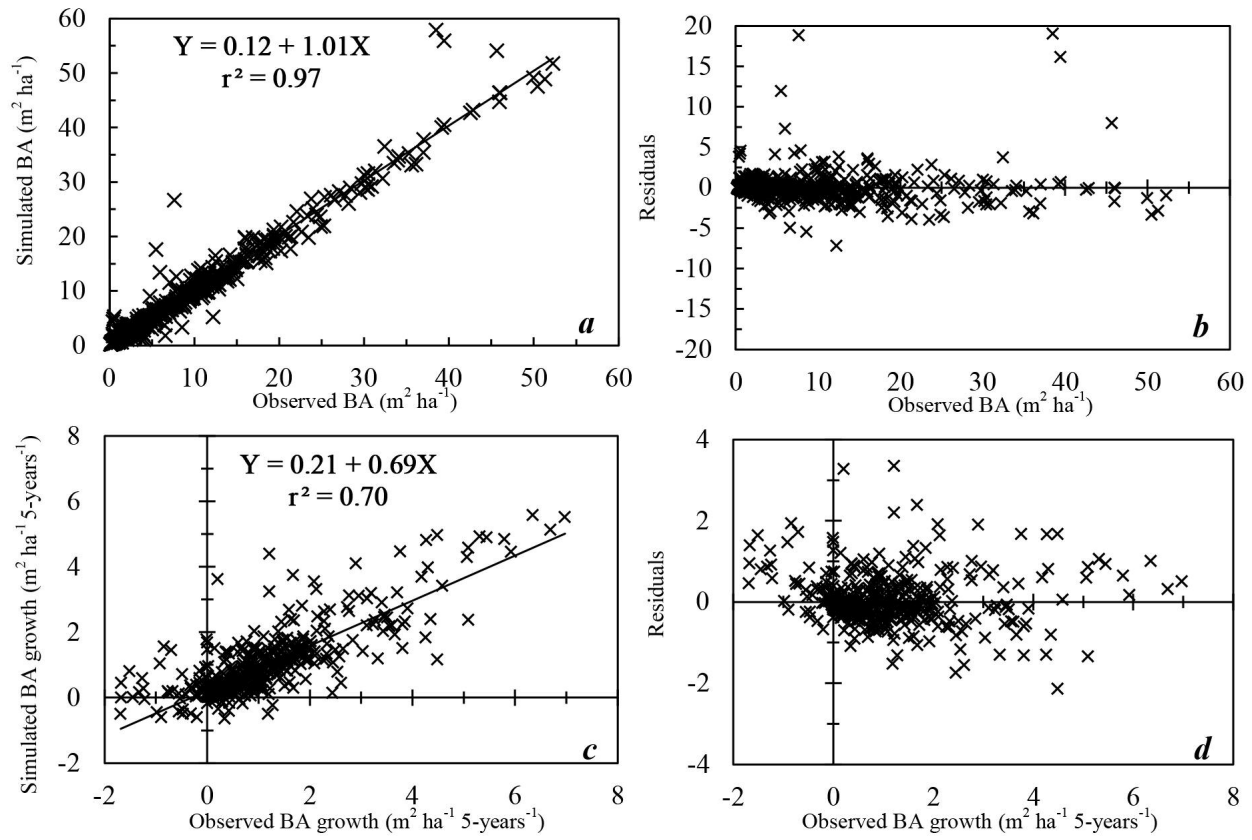

Fig. 3. (a) Linear regression model for modelled vs. observed basal area (BA, $m^{2}$ ha ${ }^{-1}$ ), (b) residual plot for BA associated with the linear model in the preceding graph, $(c)$ linear regression model for modelled vs. observed BA growth $\left(\mathrm{m}^{2} \mathrm{ha}^{-1} 5\right.$-years $\left.{ }^{-1}\right)$, and $(d)$ residual plot for BA growth associated with the linear model in the preceding graph. Comparisons are based on 35 permanent sample plots.
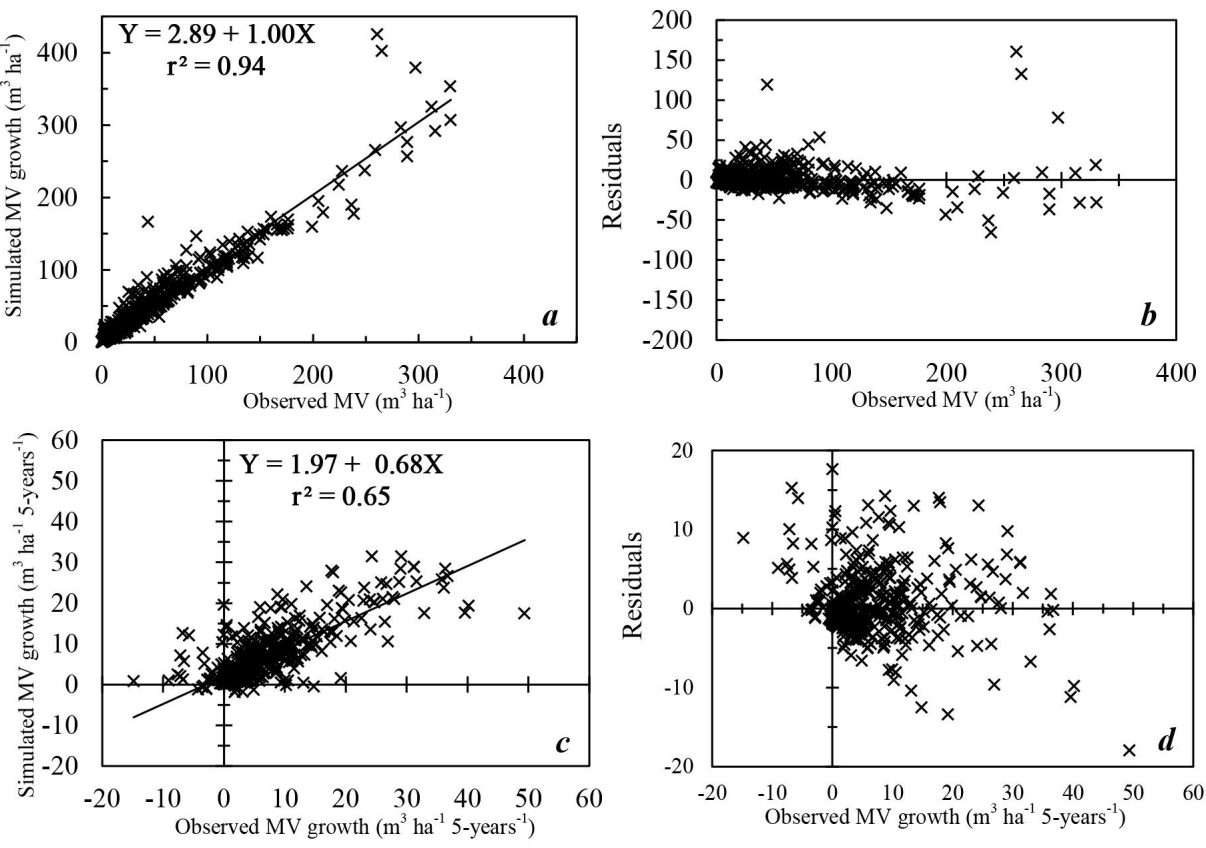

Fig. 4. (a) Linear regression model for modelled vs. observed merchantable volume (MV, $\mathrm{m}^{3} \mathrm{ha}^{-1}$ ), (b) residual plot for MV associated with the linear model in the preceding graph, $(c)$ linear regression model for modelled vs. observed MV growth $\left(\mathrm{m}^{3}\right.$ ha $^{-1} 5$-years ${ }^{-1}$ ), and $(d)$ residual plot for MV growth associated with the linear model in the preceding graph. Comparisons are based on 35 permanent sample plots. 
indicating suitability of the linear model (Sullivan 2007). Values of BIAS, ME, and RMSE, along with results of tests of significance of regression coefficients for growth and yield are presented in Table 3. Generally, BIAS associated with predicting BA $\left(\mathrm{m}^{2} \mathrm{ha}^{-1}\right)$ was -0.17 , BA growth $\left(\mathrm{m}^{2} \mathrm{ha}^{-1} 5\right.$-years $\left.{ }^{-1}\right)$ $0.05, \mathrm{MV}\left(\mathrm{m}^{3} \mathrm{ha}^{-1}\right)-3.06$, and MV growth $\left(\mathrm{m}^{3} \mathrm{ha}^{-1}\right.$ 5years $\left.{ }^{-1}\right)$ -0.03 . Highest $\mathrm{ME}$ was 0.96 with predicting $\mathrm{BA}$, whereas it was 0.93 with predicting MV. ME values for BA growth and MV growth were 0.69 and 0.64, respectively. Similarly, RMSE's were 1.73 and 0.66 for BA and BA growth and 13.99 and 4.51 for MV and MV growth, respectively. Separate $t$ and $F$ tests produced high $P$ values for BA yield, demonstrating that estimated slope and intercept were not significantly different from unity and zero. This was also the case for the slope of the regression line fitted to the observed and modelled MV data pairs $(P=0.63)$. However, the slopes and intercepts of the regression lines fitted to the $\mathrm{BA}$ and $\mathrm{MV}$ growth data (observed vs. modelled) showed significant deviation from both unity and zero $(P<0.05)$.

\section{Model accuracy in individual PSP assessment Species distribution probability}

Results of the $\chi^{2}$ analysis according to species' BA in all PSPs are shown in Table 4. Twenty-nine PSPs provided overall good agreement $(P>0.9)$ between modelled and observed species distributions; five PSPs produced $P$-values between 0.3 and 0.9 and one PSP showed poor agreement $(P<0.3)$.

\section{Stand yields}

Results of the BA yield analysis are shown in Table 5 and Fig. 5. Twenty-one PSPs were in the best class, based on ME [0.75-1.00]. Nine PSPs were in the good [0.45-0.75], two in the medium [0.0-0.44], and three in the poor class (Fig. $5 d$ ). Minimum value of ME was -3.80 for PSP 615. Twenty-two PSPs were in the best to good classes, based on RMSE-evaluation criteria $\leq 2.0$, and 11 were in the medium class [2.01-4.00]. The highest RMSE was 9.03 for PSP 460. Fourteen PSPs were in the best $(\leq 0.50)$ and two in the poor $(>3.00)$ classes, based on BIAS. The other 19 PSPs were in the medium to good classes (Fig. 5f). Greatest BIAS determined was -3.39 for PSP 460 . In summary, over $90 \%$ of PSPs were in best to medium classes, as defined by ME, RMSE, and BIAS.

Results of MV yield analysis are shown in Table 6 and Fig. 6 . In the evaluation of MV yield, 22 PSPs were in best and good $(\geq 0.45)$, six in medium [0.0-0.44], and seven in poor $(<0.00)$ classes. Fourteen PSPs were in the best and good classes, based on the RMSE criteria $\leq 10.00$, nine in the medium [10.01-20.00] and 12 in the poor classes $(>20.00)$. Twelve PSPs were in the best class based on a BIAS criteria $\leq 5.00$, eight in the good $[5.01,15.00], 13$ in the medium $[15.01,30.00]$, and two in the poor classes $(>30.00)$.

\section{Stand growth rate}

Results for BA growth analysis are presented in Table 5 and Fig. 5 . ME values for BA growth were generally low: seven PSPs were in the best and good class $(>0.45)$ based on ME, 11 in the medium [0.00-0.44], and 17 in the poor class. Lowest value of ME was -4.07 for PSP 702. Lower ME values reflect the fact that growth rates were more variable than yield data. Eighteen PSPs were in the best and good classes $(\leq 1.00)$ based on RMSE and 15 in the medium class [1.01-2.00]. Highest
Table 4. Probability of species distribution of 35 permanent sample plots (PSPs) across all ecoregions of Nova Scotia, based on $B A\left(\mathrm{~m}^{2}\right.$ ha- $\left.^{-1}\right)$

\begin{tabular}{|c|c|c|c|}
\hline Ecoregion & PSP \# & $x^{2}$ & $p$ \\
\hline \multirow[t]{2}{*}{1} & 615 & 16.21 & 0.76 \\
\hline & 1467 & 7.13 & 0.52 \\
\hline \multirow[t]{2}{*}{2} & 846 & 2.77 & 1 \\
\hline & 1535 & 1.25 & 1 \\
\hline \multirow[t]{4}{*}{3} & 96 & 1.85 & 1 \\
\hline & 702 & 0.70 & 1 \\
\hline & 847 & 0.47 & 1 \\
\hline & 1626 & 1.20 & 1 \\
\hline \multirow[t]{6}{*}{4} & 63 & 0.91 & 1 \\
\hline & 460 & 7.71 & 1 \\
\hline & 726 & 0.57 & 1 \\
\hline & 760 & 12.98 & 0.97 \\
\hline & 1041 & 5.32 & 1 \\
\hline & 1361 & 1.38 & 1 \\
\hline \multirow[t]{3}{*}{5} & 429 & 1.11 & 0.95 \\
\hline & 898 & 7.86 & 1 \\
\hline & 958 & 6.74 & 1 \\
\hline \multirow[t]{4}{*}{6} & 570 & 0.47 & 1 \\
\hline & 881 & 14.25 & 0.99 \\
\hline & 1272 & 25.22 & 0.05 \\
\hline & 1724 & 0.31 & 1 \\
\hline \multirow[t]{10}{*}{7} & 74 & 0.45 & 1 \\
\hline & 578 & 6.11 & 1 \\
\hline & 735 & 9.76 & 0.88 \\
\hline & 836 & 1.67 & 1 \\
\hline & 893 & 1.10 & 1 \\
\hline & 1098 & 0.29 & 1 \\
\hline & 1130 & 1.29 & 1 \\
\hline & 1291 & 5.47 & 1 \\
\hline & 1559 & 15.70 & 0.87 \\
\hline & 1718 & 2.09 & 1 \\
\hline \multirow[t]{2}{*}{8} & 1022 & 0.81 & 1 \\
\hline & 123 & 5.14 & 0.64 \\
\hline \multirow[t]{2}{*}{9} & 368 & 2.56 & 0.98 \\
\hline & 587 & 2.48 & 1 \\
\hline
\end{tabular}

$\chi^{2}$ (Chi)-square test; $P$ showing the probability of occurrence of same species distribution: Probability values range from 0 to 1 , where 0 means compared distributions are significantly different from each other and 1 , corresponds to matching distributions.

RMSE values for growth rate were 2.17 and 2.13 for PSPs 460 and 1467, respectively. Seventeen PSPs were in the best BIAS class $(\leq 0.25), 16$ in good and medium classes $(\leq 1.00)$, and the remaining two in the poor class $(>1.00)$. Most of PSPs were in the best and good classes $(\geq 0.55)$, showing overall low BIAS (Fig. 5c). Highest BIAS for BA growth was 1.49 for PSP 1272. Overall for the BA growth analysis, 51\% PSPs (based on ME) were in the best to medium classes, whereas 94\% PSPs were in the best to medium classes based on RMSE and BIAS. 
Table 5. JABOWA-3 evaluations for basal area (BA) growth and yield of 35 permanent sample plots (PSPs) from nine ecoregions of Nova Scotia

\begin{tabular}{|c|c|c|c|c|c|c|c|}
\hline \multirow[b]{2}{*}{ Ecoregion } & \multirow[b]{2}{*}{ PSP \# } & \multicolumn{3}{|c|}{$\begin{array}{c}\text { Growth, BA } \\
\left(\mathrm{m}^{2} \mathrm{ha}^{-1} \text { 5-years }\right. \\
\end{array}$} & \multicolumn{3}{|c|}{ Yield, BA $\left(\mathrm{m}^{2} \mathrm{ha}^{-1}\right)$} \\
\hline & & ME & RMSE & BIAS & ME & RMSE & BIAS \\
\hline \multirow[t]{2}{*}{1} & 615 & -0.66 & 0.18 & -0.13 & -3.80 & 0.39 & -0.28 \\
\hline & 1467 & 0.34 & 2.13 & -0.51 & 0.93 & 3.26 & -1.16 \\
\hline \multirow[t]{2}{*}{2} & 846 & -0.09 & 0.75 & 0.46 & 0.92 & 1.14 & -0.43 \\
\hline & 1535 & -2.03 & 0.63 & 0.29 & 0.98 & 0.69 & -0.09 \\
\hline \multirow[t]{4}{*}{3} & 96 & 0.27 & 1.05 & -0.10 & 0.55 & 2.07 & -0.72 \\
\hline & 702 & -4.07 & 1.71 & 1.01 & 0.95 & 1.66 & -0.18 \\
\hline & 847 & -0.70 & 0.55 & 0.12 & 0.93 & 0.79 & -0.60 \\
\hline & 1626 & -0.27 & 1.03 & 0.10 & 0.92 & 1.29 & 0.94 \\
\hline \multirow[t]{6}{*}{4} & 63 & -0.08 & 1.55 & 0.31 & 0.97 & 1.24 & 0.06 \\
\hline & 460 & 0.05 & 2.17 & -0.80 & -0.97 & 9.03 & -3.39 \\
\hline & 726 & 0.68 & 0.72 & 0.08 & 0.47 & 2.06 & -1.27 \\
\hline & 760 & 0.03 & 0.88 & 0.55 & 0.68 & 3.59 & -0.48 \\
\hline & 1041 & 0.11 & 1.02 & 0.68 & 0.93 & 1.68 & -0.19 \\
\hline & 1361 & 0.84 & 0.59 & 0.17 & 0.38 & 3.70 & -1.68 \\
\hline \multirow[t]{3}{*}{5} & 429 & -3.43 & 1.08 & 0.61 & 0.93 & 1.68 & 1.33 \\
\hline & 898 & 0.45 & 1.72 & -0.56 & 0.69 & 3.17 & -2.24 \\
\hline & 958 & 0.16 & 1.00 & 0.25 & 0.57 & 2.48 & -1.18 \\
\hline \multirow[t]{4}{*}{6} & 570 & 0.03 & 0.90 & 0.25 & 0.54 & 1.26 & 0.47 \\
\hline & 881 & 0.30 & 1.69 & 0.04 & 0.90 & 1.71 & 1.01 \\
\hline & 1272 & -2.09 & 1.95 & 1.49 & 0.57 & 5.00 & 4.13 \\
\hline & 1724 & 0.79 & 0.92 & 0.58 & 0.97 & 1.17 & -0.50 \\
\hline \multirow[t]{10}{*}{7} & 74 & -0.32 & 0.31 & -0.06 & 0.96 & 0.47 & -0.40 \\
\hline & 578 & 0.02 & 1.15 & 0.56 & 0.69 & 2.43 & -1.70 \\
\hline & 735 & 0.65 & 1.14 & 0.59 & 0.95 & 2.69 & 2.01 \\
\hline & 836 & -2.08 & 0.67 & 0.17 & 0.98 & 0.54 & 0.30 \\
\hline & 893 & 0.10 & 0.59 & 0.11 & 0.94 & 0.90 & 0.66 \\
\hline & 1098 & -0.87 & 0.30 & 0.01 & 0.76 & 0.31 & 0.23 \\
\hline & 1130 & 0.29 & 0.37 & 0.03 & -0.57 & 1.49 & -0.39 \\
\hline & 1291 & 0.53 & 1.10 & 0.25 & 0.97 & 1.54 & -0.69 \\
\hline & 1559 & -0.80 & 0.79 & 0.07 & 0.91 & 1.13 & 0.86 \\
\hline & 1718 & -0.08 & 1.40 & -0.63 & 0.92 & 2.17 & -1.69 \\
\hline \multirow[t]{2}{*}{8} & 1022 & 0.80 & 0.31 & 0.03 & 0.50 & 2.36 & -2.10 \\
\hline & 123 & -0.41 & 0.51 & 0.34 & 0.44 & 1.23 & 0.89 \\
\hline \multirow[t]{2}{*}{9} & 368 & -0.99 & 1.27 & -0.34 & 0.91 & 1.84 & -0.17 \\
\hline & 587 & -2.60 & 1.16 & -0.56 & 0.89 & 1.89 & -0.64 \\
\hline
\end{tabular}

RMSE $=$ root mean square error

$\mathrm{ME}=$ model efficiency in assessing the predictive power of the model

Analysis of MV growth is shown in Table 6 and Fig. 6. ME for MV growth, six PSPs were in best and good classes (>0.45), 11 in the medium class [0.0-0.44], and 18 in the poor class. Fifteen PSPs were in the best and good classes for RMSE $(\leq 5.00), 11$ in the medium class [5.01-10.00], and 9 in the poor class (>10.00); whereas 20 PSPs were in the best and good classes based on BIAS ( $\leq 3.00), 11$ in the medium class [3.01-7.00], and four in poor class (>7.00). In summary, $51 \%$
Table 6. JABOWA-3 evaluations for merchantable volume (MV) growth and yield of 35 permanent sample plots (PSPs) from nine ecoregions of Nova Scotia

\begin{tabular}{|c|c|c|c|c|c|c|c|}
\hline \multirow[b]{2}{*}{ Ecoregion } & \multirow[b]{2}{*}{ PSP \# } & \multicolumn{3}{|c|}{$\begin{array}{c}\text { Growth, MV } \\
\left(\mathrm{m}^{3} \mathrm{ha}^{-1} \text { 5-years }\right. \\
\text {-1) }\end{array}$} & \multicolumn{3}{|c|}{ Yield, MV $\left(\mathrm{m}^{3} \mathrm{ha}^{-1}\right)$} \\
\hline & & ME & RMSE & BIAS & ME & RMSE & BIAS \\
\hline \multirow[t]{2}{*}{1} & 615 & -3.03 & 0.58 & -0.45 & -3.07 & 1.25 & -0.44 \\
\hline & 1467 & 0.31 & 8.95 & -6.79 & 0.78 & 19.37 & -16.84 \\
\hline \multirow[t]{2}{*}{2} & 846 & -1.12 & 8.16 & 5.25 & 0.40 & 13.26 & 10.66 \\
\hline & 1535 & -1.08 & 10.09 & -5.63 & 0.70 & 19.02 & -17.04 \\
\hline \multirow[t]{4}{*}{3} & 96 & -0.06 & 15.39 & 2.56 & 0.45 & 21.38 & 16.20 \\
\hline & 702 & -6.68 & 21.84 & 17.38 & 0.72 & 33.66 & 21.60 \\
\hline & 847 & -0.07 & 6.13 & -0.67 & 0.54 & 11.96 & -10.60 \\
\hline & 1626 & -0.56 & 4.08 & -0.74 & 0.96 & 4.92 & -0.22 \\
\hline \multirow[t]{6}{*}{4} & 63 & -0.01 & 11.64 & -1.31 & 0.98 & 7.87 & 2.12 \\
\hline & 460 & 0.01 & 10.76 & -4.46 & -0.97 & 56.17 & -29.24 \\
\hline & 726 & 0.75 & 4.06 & 0.77 & 0.88 & 7.14 & -3.83 \\
\hline & 760 & -5.20 & 6.06 & -2.57 & 0.11 & 31.28 & -23.12 \\
\hline & 1041 & 0.37 & 3.24 & -1.37 & 0.63 & 17.23 & -15.18 \\
\hline & 1361 & 0.69 & 6.27 & -3.50 & -0.01 & 37.47 & -25.75 \\
\hline \multirow[t]{3}{*}{5} & 429 & 0.15 & 4.73 & 4.46 & 0.95 & 8.22 & 4.75 \\
\hline & 898 & -0.27 & 10.23 & -5.62 & 0.63 & 27.28 & -20.45 \\
\hline & 958 & 0.14 & 4.81 & -0.58 & 0.44 & 18.31 & -13.54 \\
\hline \multirow[t]{4}{*}{6} & 570 & -0.17 & 7.75 & 3.65 & -2.53 & 12.85 & 11.10 \\
\hline & 881 & 0.26 & 9.98 & -1.50 & 0.93 & 10.69 & -7.56 \\
\hline & 1272 & 0.89 & 2.24 & 0.82 & 0.99 & 3.14 & 1.79 \\
\hline & 1724 & 0.40 & 11.61 & 9.48 & 0.82 & 23.78 & 17.20 \\
\hline \multirow[t]{10}{*}{7} & 74 & 0.23 & 2.04 & -0.22 & 0.96 & 2.28 & -1.81 \\
\hline & 578 & 0.32 & 6.29 & 2.17 & -0.35 & 33.10 & -31.07 \\
\hline & 735 & 0.51 & 7.88 & 5.57 & 0.92 & 17.57 & 11.25 \\
\hline & 836 & -1.80 & 3.49 & -0.67 & 0.98 & 2.56 & -0.82 \\
\hline & 893 & -1.65 & 3.30 & -2.57 & 0.79 & 8.17 & -5.78 \\
\hline & 1098 & -2.30 & 1.64 & -0.78 & 0.00 & 4.15 & -3.70 \\
\hline & 1130 & 0.09 & 2.89 & 0.11 & 0.12 & 7.87 & -1.26 \\
\hline & 1291 & 0.48 & 8.42 & -5.84 & 0.58 & 32.40 & -28.88 \\
\hline & 1559 & -0.51 & 3.80 & -1.00 & 0.98 & 2.94 & -0.45 \\
\hline & 1718 & -2.66 & 14.67 & -13.27 & -0.64 & 45.17 & -36.29 \\
\hline \multirow[t]{2}{*}{8} & 1022 & 0.18 & 4.24 & 2.10 & 0.92 & 6.14 & 5.17 \\
\hline & 123 & 0.56 & 0.71 & 0.43 & 0.90 & 1.34 & 0.71 \\
\hline \multirow[t]{2}{*}{9} & 368 & -38.15 & 8.84 & -6.95 & -0.26 & 28.90 & -19.84 \\
\hline & 587 & -1.62 & 10.68 & -8.46 & 0.12 & 30.53 & -22.07 \\
\hline
\end{tabular}

RMSE $=$ root mean square error

$\mathrm{ME}=$ model efficiency in assessing the predictive power of the model

of PSPs were modelled poorly (i.e., low ME), whereas $74 \%$ and $89 \%$ of PSPs were modelled reasonably well, based on RMSE and BIAS.

Comparisons of species' change (modelled vs. observed species' BA) for PSPs 578, 615, 1272, and 1361 are shown in Fig. 7. The four PSPs were examined individually to determine reasons for discrepancy between modelled and fieldbased values. Two PSPs (578 and 1272) showed reasonable 

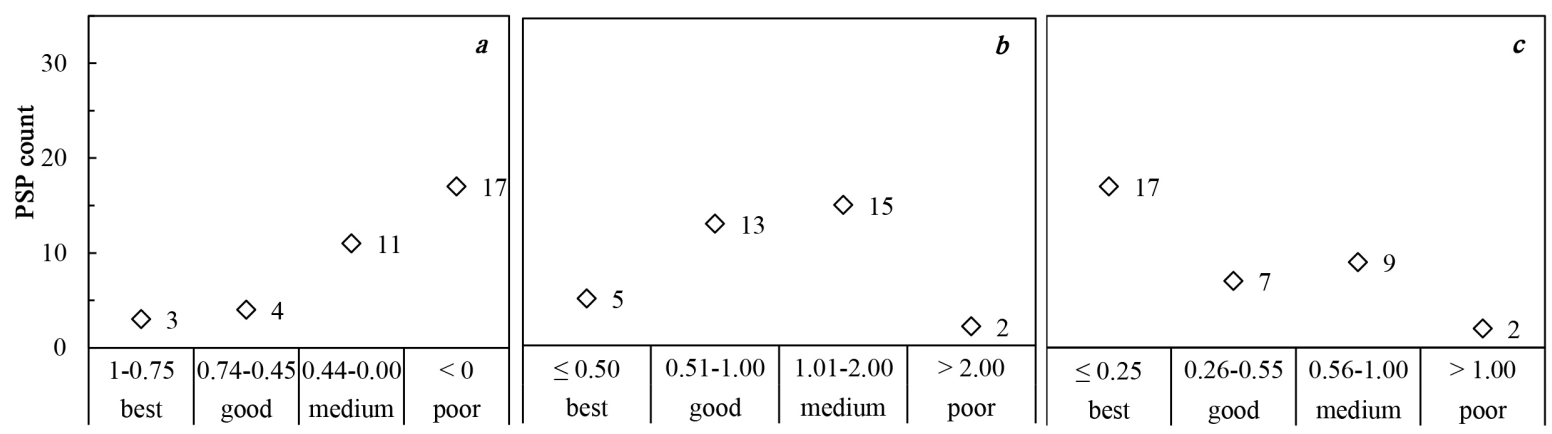

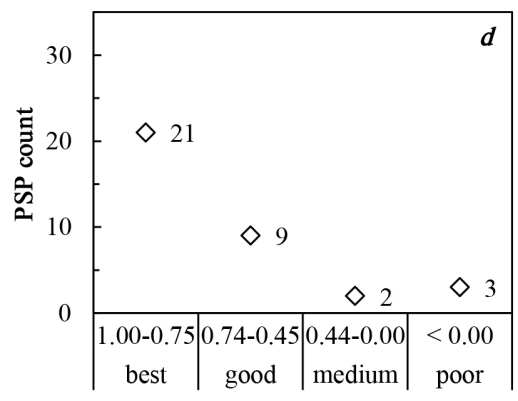

ME Classes

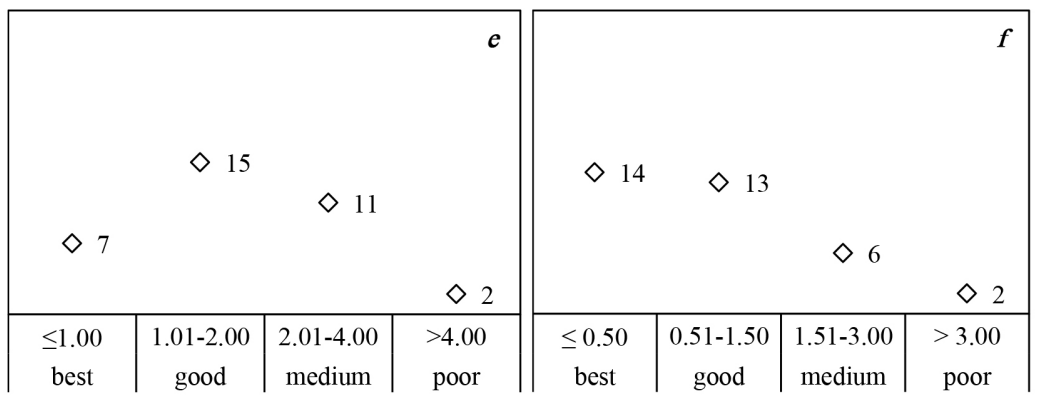

RMSE Classes
BIAS Classes

Fig. 5. JABOWA-3 evaluations based on BA growth ( $\mathrm{m}^{2} \mathrm{ha}^{-1} 5$-years ${ }^{-1} ; a-c$ ) and yield (BA, $\mathrm{m}^{2} \mathrm{ha}^{-1}$; $d-f$ ) of 35 permanent sample plots (PSPs), showing frequency of PSPs by range classes of three evaluation criteria, model efficiency (ME), root mean squared error (RMSE), and BIAS (presented as absolute values].
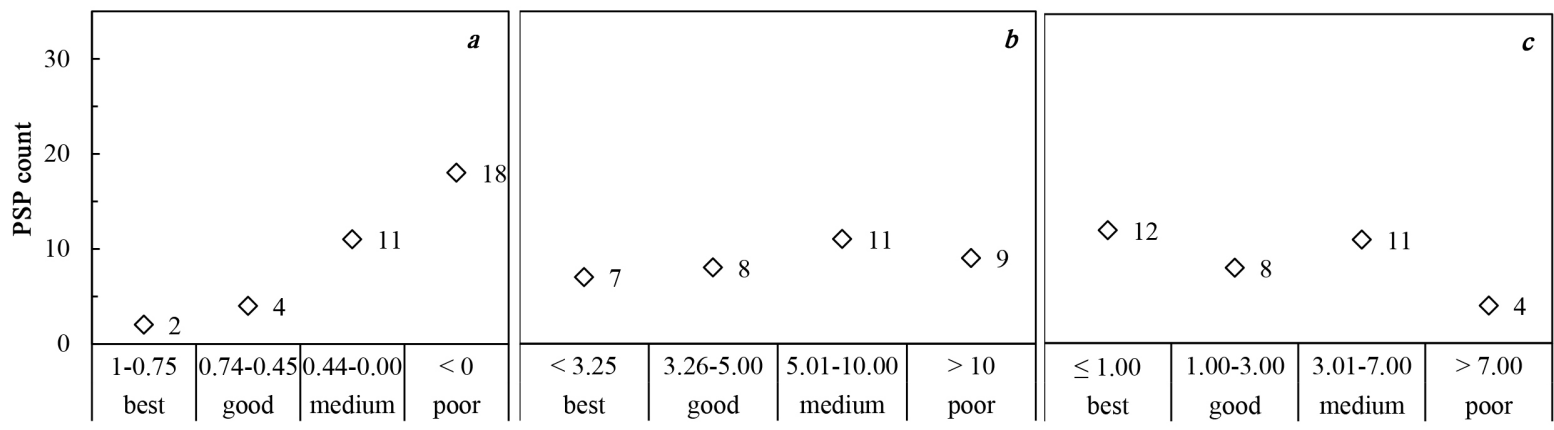

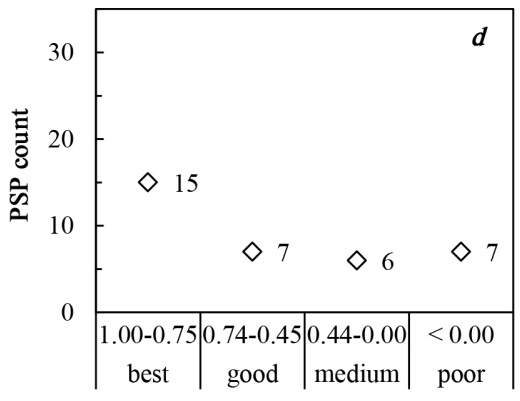

ME Classes

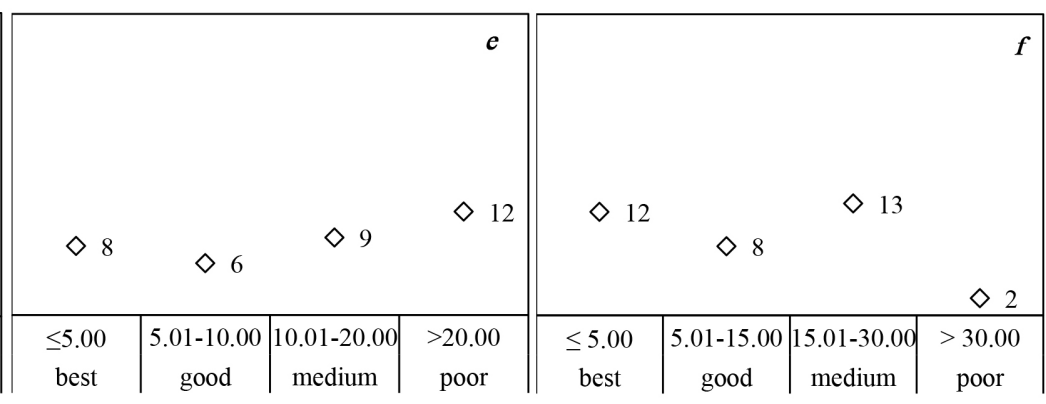

RMSE Classes
BIAS Classes

Fig. 6. JABOWA-3 evaluations based on merchantable volume growth $\left(\mathrm{m}^{3} \mathrm{ha}^{-1} 5\right.$-years $\left.{ }^{-1} ; a-c\right)$ and yield $\left(\mathrm{MV}, \mathrm{m}^{3}\right.$ ha $\left.{ }^{-1} ; d-f\right)$ of 35 permanent sample plots (PSPs), showing frequency of PSPs by range classes of three evaluation criteria, model efficiency (ME), root mean squared error (RMSE), and BIAS (presented as absolute values). 

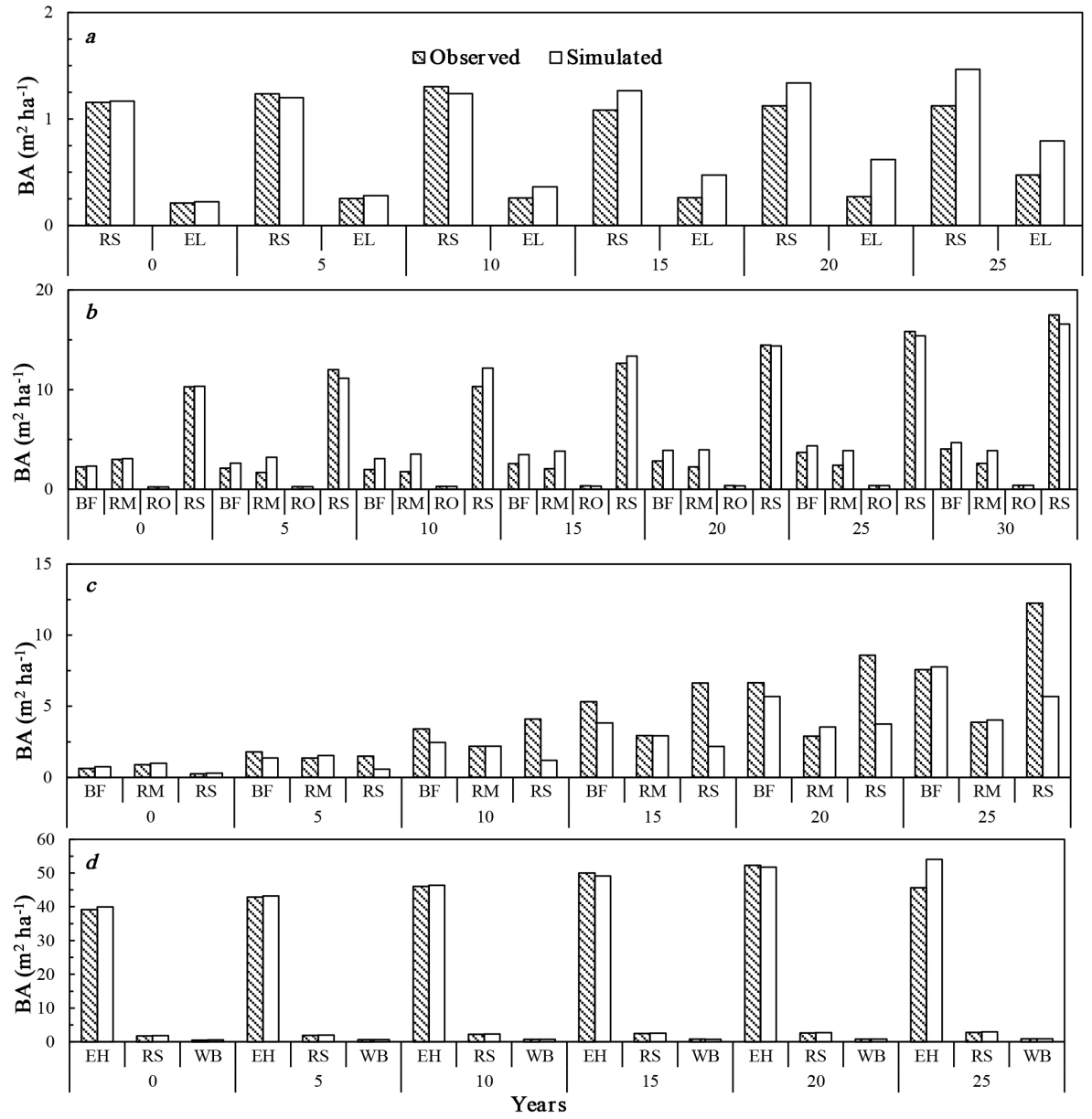

Fig. 7. Modelled vs. observed distributions of basal area (BA, $\mathrm{m}^{2}$ ha-1) by species in four permanent sample plots; a) PSP 615, b] PSP 578, $c$ ] PSP 1272, and d) PSP 1361; BF stands for balsam fir, EH eastern hemlock, EL Eastern larch RM red maple, RS red spruce, RO red oak, and WB white birch.

accuracy $(\mathrm{ME}>0.55)$ for BA yield, but low accuracy $(\mathrm{ME} \leq 0)$ for BA growth. PSP 615 showed low accuracy $(\mathrm{ME}<0)$ for both BA yield and growth. PSP 1361 showed very high accuracy with modelled $\mathrm{BA}$ growth $(\mathrm{ME}=0.84)$, but very low accuracy $(\mathrm{ME}=0.38)$ with BA yield.

\section{Discussion}

Model evaluation is an important step prior to model application. JABOWA-3 was evaluated using PSPs from diverse environmental conditions. In this study, predicted $\mathrm{BA}$ and MV provide fairly good correlation with field data $\left(r^{2}=0.97\right.$, $0.94 ; \mathrm{ME}=0.96,0.93$, respectively). The model was also able to predict species distribution fairly well. However, accuracy was lower in estimating growth data. Using a different gap model, Smith (1998) reported an $r^{2}$-value of 0.92, when comparing simulated and observed biomass (tonnes $\mathrm{ha}^{-1}$ ) for Cape Breton Island, Nova Scotia. Prediction of BA for shade-tolerant and intolerant hardwood species with the empirically based Nova Scotia Hardwood Growth and Yield Model resulted in $r^{2}$-values of 0.90 and 0.92 , respectively (O'Keefe and McGrath 2006). Another recent validation of a
JABOWA-type model in eastern Australia reported $r^{2}$-values of 0.97 and 0.59 in projecting tree diameter and height, respectively (Ngugi and Botkin 2011).

Ngugi and Botkin (2011), in validating the Ecosystem Dynamics Simulator (a JABOWA-II variant) for eastern Australia, reported a mean BIAS of $-4.7 \%$ for the prediction of BA $\left(\mathrm{m}^{2} \mathrm{ha}^{-1}\right)$ and an explanation of $89.3 \%$ of observed variation in plot BA. In our study, 94\% of PSPs were below acceptable limits for BA growth and yield based on BIAS (BA growth $\leq 1.00$ and BA yield $\leq 3.00$ ). Similarly, $89 \%$ and $94 \%$ of PSPs in MV-specified growth and yield produced BIAS values of $\leq 30.00$ and $\leq 7.00$, respectively, in comparison to modelled vs. observed values. Tree growth rates vary over the life span of trees, as they are routinely affected by temporal variations in local growing conditions. Besides, measurement errors in field data usually affect statistical analyses that rely on these data. Inaccuracies in tree measurements one year can lead to greater inaccuracies in subsequent years, especially in growth analysis, even if tree variables have been measured correctly in those subsequent years. 
Modelled species distributions based on BA $\left(\mathrm{m}^{2} \mathrm{ha}^{-1}\right)$ for 29 (83\%) out of 35 PSPs produced species distribution probability statistics $(P$ values $)>0.9$. In model validation studies, high $P$ values are considered desirable and demonstrate fairly good agreement between modelled and observed data (Yaussy 2000).

Results of separate $t$ test and $F$ tests showed that slope and intercept of fitted regression lines between observed and modelled BA (yield) were not significantly different from unity and zero. However, analysis between modelled and observed BA growth and MV growth, slope and intercept were significantly different from unity and zero $(\alpha=0.05)$. The regression of modelled on observed is not expected to be consistent with unity for stochastic models such as JABOWA; therefore, careful examination is suggested for interpretation of statistical tests, especially the $F$ test (Dent and Blackie 1979). Autocorrelation in errors related to the observed data cause serious problems with the test (Mayer et al. 1994). In addition, investigations using one component of accuracy to test the other, such as a separate $t$ test and $F$ test, have reported problems in model validation (Hann 1980 and Weisekittel 2011). Harrison (1990) found the $F$ test inappropriate and noted that bias in parameter estimates may reject a valid model, suggesting the use of descriptive statistics and subjective tests in model validation instead. Thornton and Hansen (1996) also found the test severely ambiguous and inappropriate for complex simulation models. Since models are the abstraction of natural systems, they cannot pass all tests of validation. Furthermore, errors in measured tree data tend to impact assessments of growth more than yield. In this study, further tests based on BIAS, ME, $r^{2}$, and RMSE generally demonstrate the suitability of the model for growth and yield prediction.

Four typical PSPs were selected to analyze the reasons why the model had poor prediction accuracy for both BA growth and yield for some stands.

For PSP 615, the model predicted both BA growth $(\mathrm{ME}=$ $-0.66)$ and yield $(\mathrm{ME}=-3.80)$ poorly. Detail analysis indicated that the PSP 615 was initially under-stocked. Red spruce (Picea rubens Sarg.) accounted for $80 \%$ and eastern larch (Larix laricina [Du Roi] K. Koch) $20 \%$ of total BA (Table 1). For red spruce, model predictions of BA yield agreed fairly well with observed values from year 0 to year 10 (Fig. 7a). However, the model overestimated red spruce BA from year 15 to year 25 (Fig. 7a). Field records indicated that a single large red spruce tree died in the plot during years 10 to 15 , which led to a sudden reduction of plot BA from $1.3 \mathrm{~m}^{2} \mathrm{ha}^{-1}$ to $1.1 \mathrm{~m}^{2} \mathrm{ha}^{-1}$. Obviously, the model failed to predict the death of this large tree and caused overestimation of red spruce BA. Serial correlation in predicted data also contributed to poor prediction accuracy because a minor discrepancy in year 10 caused discrepancies to appear in succeeding years.

For eastern larch, BA hardly changed from year 0 to year 20 , but suddenly increased in year 25 . Field records indicated that there was only one eastern larch tree with an initial DBH of $10.4 \mathrm{~cm}$ in year 0 ; its diameter increased $1.4 \mathrm{~cm}$ over 20 years. The tree was most likely unhealthy and growing very slowly. Clearly, JABOWA is incapable of predicting growth of unhealthy trees. The sudden increase in BA of eastern larch in year 25 was caused by ingrowth. Ingrowth is often associated with small trees already existing in the stand with DBHs less than $9.1 \mathrm{~cm}$. JABOWA does not have the capability to account for ingrowth in a particular year as ingrowth is modelled in JABOWA as a random event.

For PSPs 578 and 1272, model predictions for BA yield were fairly good, but BA growth was poor (Table 5). In PSP 578 , red spruce dominated the stand contributing to $71 \%$ of total plot BA and the remaining $29 \%$ due to the presence of balsam fir, red maple (Acer rubrum L.), and red oak (Quercus rubra $L$.). The model consistently overestimated balsam fir and red maple BA from years 5 to 30. Field records indicated the presence of one old red maple and six balsam fir trees during years 5 to 15 . The BA of red spruce was overestimated for years 10 and 15 . This could be attributed to the fact that two large trees died during the time period. Again, these results clearly indicate the model's inability to predict the death of a specific tree at a specific time. Lowered discrepancy in red spruce BA yield between observed and modelled at year 10 could be attributed to four ingrowth trees appearing during years 15 to 20 .

In PSP 1272, initially balsam fir and red maple were the major species, while the red spruce share was low. Balsam fir BA was underestimated from years 5 to 20 and red spruce from years 5 through to the end of the observation period. Field records show ample ingrowth (balsam fir: 21; red spruce: 29 trees) over the comparison period. Red maple BA modelled and observed agreed fairly well, except at year 20 . This incongruity was caused by the death of three large-size red maple trees.

In PSP 1361, eastern hemlock (Tsuga canadensis [L.] Carrière) was the dominant species, contributing to $95 \%$ of the total plot BA. The modelled BA was close to its observed counterpart until year 20 . The model overestimated BA yield at year 25. Field records indicated that eight hemlock trees died in year 25. This sudden decline contributed to an overall low ME (0.38) for BA yield, even though modelled and observed BA for the first initial 20 years were quite similar. However, high ME (0.84) with predicting BA growth was attained, given that the period of discrepancy was not included in the comparison.

In summary, JABOWA could not predict mortality of some larger trees, which led to poor model performance for some PSPs. In general, tree mortality is a sporadic process triggered by many internal and external factors (Taylor and MacLean 2007, Weiskittel et al. 2011). Although we understand some mechanisms that trigger tree death, it is difficult, if not impossible, to predict the death of particular trees at specific times. Mortality is the least reliable process to replicate in forest growth simulators (Weiskittel et al. 2011). Similar to other gap models, JABOWA-3 can simulate the probability of mortality as a function of tree age and competition; however, it does not consider "catastrophic mortality" due to external events associated with insect infestations, diseases, and wildfires (Botkin 1993, Weiskittel et al. 2011).

Another source of discrepancy between model predictions and field observations is associated with tree ingrowth. Trees being counted as ingrowth were small trees that existed in the PSP, which were left unrecorded during field surveys. Similar to tree mortality, the best solution is to consider ingrowth as a probability function (Weiskittel et al. 2011). Furthermore, since growth and yield data can be represented as time series, the data can carry error from one time period to the next. 
Therefore, serial correlation can contribute to low prediction accuracy, especially for disturbed stands. Statisticians have developed methods to deal with problems related to serial correlation. However, this is beyond the scope of this paper.

Reduced model performance with respect to MV may have been caused by (i) observed tree-height data usually having lower accuracy and reliability (functioning as poor comparison data), and (ii) height growth in JABOWA-3 is treated with a simplified quadratic function of diameter, which is known to fail for dense forests (Ngugi and Botkin 2011).

\section{Conclusions}

The evaluation of JABOWA-3 was carried out to determine its suitability in producing growth and yield predictions based on important stand-level metrics. Two commonly used measures in applied forestry, BA and MV, were tested by comparing predicted values against observed values from 35 PSPs distributed across Nova S'cotia. The accuracy of predicting species distribution over time was also assessed using a $\chi^{2}$ test. We found that JABOWA-predicted BA yields agreed fairly well with observed yields in stands without disturbance. Tree mortality due to natural disturbance and ingrowth were the major reasons of low prediction accuracy for some stands, as a result of the model's inability to predict time-specific tree death and ingrowth. Overall comparison of modelled and observed BA and MV produced $r^{2}$ values of 0.97 and 0.94 and model efficiencies (ME) of 0.96 and 0.93 . The model also predicted changes in species composition with high accuracy for most plots considered in this study $(P>0.9)$.

\section{Acknowledgements}

The authors would like to acknowledge the Nova Scotia Department of Natural Resources and Canadian Soil Information Service, Agriculture and Agri-Food Canada for providing data and other forms of support. The authors are also grateful to the (i) Higher Education Commission of Pakistan for providing financial support to Mr. Ashraf for his doctoral studies at the University of New Brunswick (UNB), and (ii) Huang Qingqing and Jin Qi, visiting scholars to the Faculty of Forestry and Environmental Management, UNB, for help in data processing and computer programming.

\section{References}

Agriculture and Agri-Food Canada. 2011. Canadian Soil Information Service [online]. Available at http://res.agr.ca/cansis/ [Accessed June 05, 2012].

Battaglia, M. and P.J. Sands. 1998. Process-based forest productivity models and their application in forest management. For. Ecol. Manage. 102: 13-32.

Botkin, D.B. 1993. Forest Dynamics: An Ecological Model. Oxford University Press, NY. 309 p.

Botkin, D.B., J.F. Janak and J.R. Wallis. 1972a. Rationale, limitations, and assumptions of a northeastern forest growth simulator. IBM Journal of Research and Development 16: 101-116.

Botkin, D.B., J.F. Janak and J.R. Wallis. 1972b. Some ecological consequences of a computer model of forest growth. Journal of Ecology 60: 849-872.

Botkin, D.B. and H.J. Schenk. 1996. History and rationales of the JABOWA model of forest growth. In Review and Analysis of JABOWA and Related Forest Models and their use in Climate Change Studies. pp. 11-162. NCASI Technical Bulletin 717. National Council of the Paper Industry for Air and Stream Improvement, Inc., Research Triangle Park, NC.
Burkhart, H.E. 1990. Status and future of growth and yield models. In V.J. LaBau and T. Cunia (eds.). State-of-the-art methodology of forest inventory: a symposium proceedings. pp. 409-414. Gen. Technical Report PNW GTR-263. USDA Forest Service. Portland, OR.

Burkhart, H.E. 2003. Suggestions for choosing an appropriate level for modelling forest stands. In A. Amaro, D. Reed and P. Soares (eds.). Modelling Forest Systems. pp. 3-10. CABI Publishing., Wallingford, UK.

Davis, L.S., K.N. Johnson, P.S. Bettinger and T.E. Howard. 2001. Forest Management. McGraw-Hill, New York. 804 p.

Dent, J.B. and M.J. Blackie. 1979. Systems Simulation in Agriculture. Applied Science Publishers Ltd., London, UK. 180 p.

Environment Canada. 2011. National Climate Data and Information Archive [online]. Available at http://www.climate.weatheroffice.gc.ca/Welcome_e.html [Accessed June 03, 2012].

Hann, D.W. 1980. Development and evaluation of an even- and uneven aged ponderosa pine/Arizona fescue stand simulator. Research Paper INT-267. USDA Forest Service, Ogden, UT. 95 p.

Harrison, S.R. 1990. Regression of a model on real-system output: An invalid test of model validity. Agri. Syst. 34: 183-190.

Hinckley, T.M. et al. 1996. Use of the JABOWA family of individual-tree based models for exploration of forest responses to global climate change. In Review and Analysis of JABOWA and Related Forest Models and Their Use in Climate Change Studies. pp. II1-II54. NCASI Technical Bulletin 717. National Council of the Paper Industry for Air and Stream Improvement, Inc., Research Triangle Park, NC.

Honer, T.G., M.F. Ker and I.S. Alemdag. 1983. Metric timber tables for the commercial tree species of central and eastern Canada. Maritimes Forest Research Centre, Canadian Forestry Service, Fredericton NB. Information Report M-X-140. 139 p.

[IPCC] Intergovernmental Panel on Climate Change. 2007. Climate Change 2007: Synthesis Report. Contribution of Working Groups I, II and III to the Fourth Assessment Report of the Intergovernmental Panel on Climate Change [Core Writing Team, Pachauri, R.K and A. Reisinger. (eds.)]. IPCC, Geneva. 104 p.

Johnsen, K., L. Samuelson, R. Teskey, S. McNulty and T. Fox. 2001. Process models as tools in forestry research and management. For. Sci. 47: 2-8.

Kimmins, J.P. 1990. Modelling the sustainability of forest production and yield for a changing and uncertain future. For. Chron. 66: 271-280.

Kimmins, J.P. 2004. Forest Ecology: A Foundation for Sustainable Forest Management and Environmental Ethics in Forestry, 3rd Ed. Prentice Hall, Upper Saddle River, NJ. 611 p.

Kimmins, J.P., A. Brunner and D. Maily. 1995. Modeling the sustainability of managed forest: Hybrid ecosystem simulation modeling from individual tree to landscape. In Proceedings of Forest Ecosystem Working Group Session at National Convention. pp. 104-114. Society of American Foresters. Portland, MA.

Kimmins, J.P. and P. Sollins. 1989. Modelling long-term forest productivity. In D.A. Perry (ed.). Maintaining the Long-Term Productivity of Pacific Northwest Forest Ecosystems. pp. 202-220. Timber Press, Portland, OR.

Korzukhin, M.D., M. Ter-Mikaelian and R.G. Wagner. 1996. Process versus empirical models: Which approach for forest ecosystem management? Can. J. For. Res. 26: 879-887.

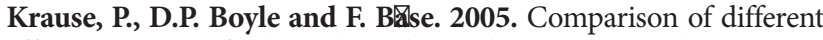
efficiency criteria for hydrological model assessment. Adv. Geosci. 5: 89-97.

Landsberg, J. 2003a. Modelling forest ecosystems: State of the art, challenges, and future directions. Can. J. For. Res. 33: 385-397.

Landsberg, J. 2003b. Physiology in forest models: History and the future. For. Bio. Model. Info. Sci. 1: 49-63.

Larocque, G.R. 2009. Forest Models. In S.E. Jorgensen and D.F. Brian (eds.). Ecological Models. Encyclopedia of Ecology. vol. 2. pp. 1663-1673. Elsevier B.V. Oxford, UK. 
Liu, J. and P.S. Ashton. 1995. Individual-based simulation models for forest succession and management. For. Ecol. Manage. 73: $157-175$.

Loehle, C. and D. LeBlanc. 1996. Model-based assessments of climate change effects on forests: A critical review. Ecol. Model. 90: $1-31$.

Makela, A. 1992. Process-oriented growth and yield models recent advances and future prospects. In T. Prehsler (eds.). Research and Yield with Emphasis on Mixed Stands. pp. 85-96. Proceedings IUFRO World Congress, Berlin.

Marshall, I.B and P.H. Schut. 1999. A National Ecological Framework for Canada - Overview: a Cooperative Product by Env. Can. and Agri. and Agri-Food Canada. Available at http://sis.agr.gc.ca/ cansis/nsdb/ecostrat/intro.html [Accessed June 03, 2012].

Mayer, D.G., M.A. Stuart and A.J. Swain. 1994. Regression of realworld data on model output: An appropriate overall test of validity. Agri. Syst. 45: 93-104.

Meldahl, R.S., R.K. Bolton and M. Eriksson. 1988. Development of a mixed species projection system for southern forests. In A.R. Ek, S.R. Shifley and T.E. Burk (eds.). Growth Modelling and Prediction, Proceedings of the IUFRO Conference 23-27 August 1987. pp. 102-109. Gen. Tech. Rep.NC-120, US Forest Service, St. Paul, MN. Mendoza, G.A. and J.K. Vanclay. 2008. Trends in forestry modelling. CAB Reviews: Perspectives in Agriculture, Veterinary Science, Nutrition and Natural Resources. 3(010) : 1-8.

Miehle, P., M. Battaglia, P.J. Sands, D.I. Forrester, P.M. Feikema and S.J. Livesley. 2009. A comparison of four process-based models and a statistical regression model to predict growth of Eucalyptus globulus plantations. Ecol. Model. 220: 734-746.

Mladenoff, D.J. 2004. LANDIS and forest landscape models. Ecol. Model. 180: 7-19.

Mohren, G.M.J. and H.E. Burkhart. 1994. Contrasts between biologically-based process models and management-oriented growth and yield models. For. Ecol. Manage. 69: 1-5.

Monserud, R.A. 2003. Evaluating forest models in a sustainable forest management context. For. Bio. Model. Info. Sci. 1: 35-47.

Montgomery, D.C., E.A. Peack and G.G. Vining. 2001. Introduction to linear regression analysis. John Wiley \& Sons, Inc. 641 p.

Nash, J.E. and J.V. Sutcliffe. 1970. River flow forecasting through conceptual models part I - A discussion of principles. J. Hydrol. 10: 282-290.

Neily, P.D., E. Quigley, L. Benjamin, B. Stewart, B. and T. Duke. 2003. Ecological land classification for Nova Scotia: Volume 1. Report DNR 2003-2. Department of Natural Resources, Truro, NS. $83 \mathrm{p}$.

Ngugi, M.R. and D.B. Botkin. 2011. Validation of a multispecies forest dynamics model using 50-year growth from Eucalyptus forests in eastern Australia. Ecol. Model. 222: 3261-3270.

Norby, R. J., K. Ogle, P. S. Curtis, F. W. Badeck, A. Huth, G. C. Hurtt, T. Kohyama and J. Peñuelas. 2001. Aboveground growth and competition in forest gap models: An analysis for studies of climatic change. Climatic Change 51: 415-447.

[NSDNR] Nova Scotia Department of Natural Resources. 2004. Nova Scotia Forest Inventory Based on Permanent Sample Plots Measured between 1999 and 2003. Report FOR 2004-3. Department of Natural Resources, Forestry Division, Truro, NS. 29 p.

2006. Forest Inventory Permanent Sample Plot Field Meas-

urement Methods And Specifications, Version 2006-1.3. Forestry Division, Department of Natural Resources, Truro, NS. 66 p.

2008. State of the Forest Report 1995-2005, Nova Scotia

Forests in Transition. Report FOR 2008-3. Department of Natural Resources, Truro, NS. 40 p.

O'Keefe, R.N. and T.P. McGrath. 2006. Nova Scotia hardwood growth and yield model. Report No. FOR 2006-2 No. 78. Department of Natural Resources, Truro, NS. 66 p.
Oreskes, N., K. Shrader-Frechette and K. Belitz. 1994. Verification, validation, and confirmation of numerical models in the earth sciences. Science 263: 641-646.

Peng, C. 2000. Growth and yield models for uneven-aged stands: Past, present and future. For. Ecol. Manage. 132: 259-279.

Pinjuv, G., E.G. Mason, M. Watt. 2006. Quantitative validation and comparison of a range of forest growth model types. For. Ecol. Manage. 236: 37-46

Porté, A. and H.H. Bartelink. 2002. Modelling mixed forest growth: A review of models for forest management. Ecol. Model. 150: $141-188$.

Pretzsch, H. 2009. Forest dynamic, growth and yields: from measurement to model. Springer Berlin and Heidelberg. 664 p.

Robinson, A.P. and A.R. Ek. 2003. Description and validation of a hybrid model of forest growth and stand dynamics for the great lakes region. Ecol. Model. 170: 73-104.

Robinson, A. P. and R.A. Monserud. 2003. Criteria for comparing the adaptability of forest growth models. For. Ecol. Manage. 172: 53-67.

Schwalm, C.R. and A.R. Ek. 2002. Developing the next generation of forest ecosystem models. In R.E. McRoberts, G.A. Reams, P.C. Van Deusen and J.W. Moser (eds.). Proceedings of Third Annual Forest Inventory and Analysis Symposium. pp. 130-136. U.S. Department of Agriculture, Forest Service, North Central Research Station, St. Paul, MN.

Shugart, H.H., 2002. Forest gap models. In H.A. Mooney and J.G. Canadell (eds.). The Earth System: Biological and Ecological Dimensions of Global Environmental Change. pp. 316-323. John Willey \& Sons, Ltd., Chichester, UK.

Shugart, H.H. and D.C. West. 1980. Forest succession models. Bioscience 30: 308-313.

Smith, M. J. 1998. An examination of forest succession in the Cape Breton highlands of Nova Scotia. M.Sc. thesis, University of New Brunswick, Fredericton, NB. 182 p.

Soares, P., M. Tomé, J.P. Skovsgaard and J.K. Vanclay. 1995. Evaluating a growth model for forest management using continuous forest inventory data. For. Ecol. Manage. 71: 251-265.

Sullivan, M. 2007. Statistics: informed decisions using data. $2^{\text {nd }}$ edit. Pearson Prentice Hall, NJ. 789 p.

Sun, H., J. Zhang, A. Duan and C. He. 2007. A review of stand basal area growth models. For. Stud. China 9: 85-94.

Taylor, S.L. and D.A. MacLean. 2007. Spatiotemporal patterns of mortality in declining balsam fir and spruce stands. For. Ecol. Manage. 253: 188-201.

Thornton, P.K. and J.W. Hansen. 1996. A note on regressing realworld data on model output. Agri. Syst. 50: 411-414.

Vanclay, J.K. 1994. Modelling forest growth and yield: applications to mixed tropical forests. CAB International Wallingford, U.K. 312 p. Vanclay, J. K. and J.P. Skovsgaard. 1997. Evaluating forest growth models. Ecol. Model. 98: 1-12.

Weiskittel, A.R., D.W. Hann, J.A. Kershaw and J.K. Vanclay. 2011. Forest Growth and Yield Modeling. John Wiley \& Sons, Ltd., UK. $415 \mathrm{p}$.

Woodbridge Associates. 2011. Economic impact analysis of timber management and supply changes of Nova Scotia's forest industry. Report prepared for Department of Natural Resources, Nova Scotia, 58 p. Available at http://www.gov.ns.ca/natr/strategy/pdf/woodbridge-may-2011.pdf [Accessed June 03, 2012].

Yang, Y., R.A. Monserud and S. Huang. 2004. An evaluation of diagnostic test and their roles in validating forest biometric models. Can. J. For. Res. 34: 619-629.

Yaussy, D.A. 2000. Comparison of an empirical forest growth and yield simulator and a forest gap simulator using actual 30-year growth from two even-aged forests in Kentucky. For. Ecol. Manage. 126: 385-398. 